ISSN: 0514-7336

DOI: http://dx.doi.org/10.14201/zephyrus20188193115

\title{
METALURGIA PREHISTÓRICA EN TIERRAS DE ANTEQUERA Y SU CONTEXTO ANDALUZ
}

\section{Prehistoric metallurgy in Tierras de Antequera and its Andalusian context}

Francisco Rodríguez Vinceiro*, Mercedes Murillo Barroso**, Luis-Efrén Fernández Rodríguez*** e Ignacio Montero Ruiz****

${ }^{*}$ Cl Ribera del Genil, 7, 1. A. 18005 Granada. Correo-e: fvinceiro@gmail.com

** Dpto. de Prehistoria y Arqueología. Facultad de Filosofía y Letras-UGR. Campus Universitario de Cartuja. 18071 Granada.Correo-e: murillobarroso@ugr.es.ID ORCID:0000-0002-2271-291X

*** Cueva de Nerja-IICN. Carretera de Maro, s/n. 29787 Nerja (Málaga). Correo-e: conservador@cuevadenerja.es

**** Instituto de Historia-CSIC. C/ Albasanz, 26-28. 28037 Madrid. Correo-e: ignacio.montero@cchs.csic.es. ID ORCID: 0000-0003-0897-1031

Recepción: 1/09/2017; Revisión: 10/11/2017; Aceptación: 9/12/2017

Resumen: La zona de Tierras de Antequera se sitúa entre los dos principales focos de investigación de la Prehistoria Reciente de la Península Ibérica: el so y el SE. Este carácter limítrofe o periférico, unido a una tradicional escasez de evidencias metalúrgicas en la zona, contribuyó a generalizar la idea de que el metal malagueńo era sistemáticamente importado de otras regiones. No obstante, a principios de los ańos 90 el Proyecto de Investigación Arqueometalúrgica de la Provincia de Málaga demostró la existencia de recursos minerales de cobre potencialmente explotables en la provincia, y de los principales elementos de la cadena de producción metalúrgica en varios yacimientos del III y II milenios Ac. Asimismo, intervenciones arqueológicas recientes han vuelto a poner de actualidad la cuestión al documentar hallazgos de producción metalúrgica prehistórica en el corazón de las Tierras de Antequera, forzándonos a replantearnos nuestras teorías sobre el modelo de apropiación de recursos cupríferos de estas comunidades.

En este trabajo revisamos las evidencias arqueometalúrgicas prehistóricas, presentamos nuevos datos de composición e isótopos de plomo, y a la luz de los últimos hallazgos realizamos una aproximación al papel socioeconómico que esta desempeñó, en su contexto andaluz y especialmente en relación a los principales focos metalúrgicos.

Palabras clave: Edad del Cobre; Edad del Bronce; Málaga; mineralizaciones de cobre; producción metalúrgica; isótopos de plomo; análisis de composición.

Aвstract: Tierras de Antequera is located between the two main research foci of the Iberian Late Prehistory: the Southwest and the Southeast. This peripheral nature, coupled with a shortage of metallurgical evidence in the area, contributed to generalize the idea that Malaga was systematically importing metals from other regions. However, the Project Investigación Arqueometalúrgica de la Provincia de Málaga showed the existence of both copper outcrops potentially exploitable by prehistoric societies, as well as significant archaeometallurgical by-products in several sites from the $3^{\text {rd }}$ and $2^{\text {nd }}$ millennium BC. Moreover, recent archaeological excavations have documented prehistoric metallurgical by-products in the core of Tierras de Antequera. This 
fact has forced us to reassess the topic and rethink our hypothesis on the models of copper production by these communities.

In this paper we review prehistoric archaeometallurgical evidence, present new elemental composition information as well as lead isotope analyses and, in light of recent findings, we approach the socio-economic role that copper production played in its broader Andalusian context and especially in relation to the two main metallurgical foci.

Key words: Copper Age; Bronze Age; Málaga; copper outcrops; copper production; lead isotope analyses; elemental composition analyses.

\section{Introducción ${ }^{1}$}

Los terrenos que conforman la provincia de Málaga han constituido tradicionalmente una especie de tierra de nadie para la investigación sobre la Prehistoria Reciente del s peninsular, que ha centrado su atención en determinadas áreas geográficas a las que se atribuyó el papel protagonista de los procesos históricos que se desarrollan en esta época, tanto desde el punto de vista de la caracterización cultural como, en definitiva, de los recursos necesarios para potenciar el conocimiento real de su pasado (Rodríguez-Vinceiro et al., 1992). Más recientemente, otros investigadores inciden (Morgado et al., 2013) en parecidos argumentos para reivindicar una mayor atención sobre otra de las supuestas periferias de tales nodos centrales de la dinámica de este proceso histórico: el Poniente Granadino. En ambos casos se trata de poner de manifiesto la polarización de la investigación sobre el IV a II milenio AC sobre determinadas zonas, en detrimento de otras que no han gozado nunca del grado de visibilidad que pudiera corresponderles por la importancia y riqueza de su patrimonio arqueológico.

1 Este trabajo ha sido respaldado por una Marie $\mathrm{Cu}$ rie Intra European Fellowship del 7th Programa Marco de la Comunidad Europea, el Programa de Captación de Talento UGR-Fellow, el proyecto I+D Metal y ámbar: modelos de circulación de materias primas en la Prehistoria Reciente de la Peninsula Ibérica (HAR2017-82685-R) financiado por el Ministerio de Economía y Competitividad y ha contado con una serie de subvenciones concedidas por la Consejería de Cultura de la Junta de Andalucía para la realización del trabajo de campo y analíticas que conforman su base documental. Los autores agradecen el apoyo técnico y humano de los sGiker de la UPV/EHU y la financiación europea (FEDER y ESF).
Volviendo a la provincia de Málaga, uno de los aspectos en los que se notan especialmente estas carencias es en el de la investigación arqueometalúrgica. Para esta parcela de la investigación, la polarización SE-SO adquiere un nuevo matiz, ya que nos encontramos, además, entre los dos principales focos metalúrgicos del $s$ de la Península Ibérica, cuya abundancia en recursos minerales ha sido clave en el devenir de sus respectivas dinámicas históricas. Por contra, la tradicional escasez de evidencias metalúrgicas locales en comparación con estas dos zonas contribuyó a generalizar la idea de que el metal malagueño era sistemáticamente importado de otras regiones andaluzas, especialmente del SE.

En este contexto, en el que algunos investigadores comenzaban ya a considerar la posibilidad de la existencia de una producción metalúrgica local en yacimientos como El Llano de la Virgen, Coín (Marqués, 1984), se desarrolló el Proyecto de Investigación Arqueometalúrgica de la provincia de Málaga (1989-1993) partiendo, esta vez, no de los restos encontrados en los yacimientos arqueológicos, sino de la prospección de los recursos minerales cupríferos en los metalotectos susceptibles de albergar estas mineralizaciones, gracias al estudio de las hojas correspondientes a Málaga del Mapa Geológico de España, escala 1: 50.000 -serie MAGNA- y el Mapa Metalogenético de Espańa, escala 1: 200.000 (Rodríguez-Vinceiro et al., 1992: 217-242; 1998: 155-172; Rodríguez-Vinceiro, 2003), que recogió información suficiente para plantear la hipótesis de la existencia de una explotación local de los limitados y puntuales recursos minerales de cobre existentes en la comarca de los Montes de Málaga, identificada como el afloramiento más extenso del Complejo Maláguide de las Zonas Internas de las Cordilleras Béticas. Se reconocía, además, aunque 
no formaba parte del ámbito del proyecto, la existencia de indicios de metalurgia en Ronda (Aguayo et al., 1987) ${ }^{2}$ y otras mineralizaciones asociadas al dominio geológico Alpujárride Occidental en la Serranía de Ronda y en los macizos peridotíticos de Ojén, Carratraca y Mijas (Romero, 2003).

\section{Indicios de minería prehistórica en las Tierras de Antequera}

Esta hipótesis sobre la existencia de una producción metalúrgica local de raíz maláguide se apoyaba en las siguientes evidencias geológicas y arqueológicas:

- Existencia de unos recursos minerales cupríferos que, aunque diseminados e incapaces de soportar una explotación continuada y a gran escala -y por estos motivos omitidos muchas veces en la cartografía geológica-, se concentran en distintos puntos de su geografía debido a anomalías geoquímicas relacionadas con fenómenos hidrotermales causados por procesos de vulcanismo que afectaron a los estratos inferiores del Maláguide, hasta constituir pequeños afloramientos susceptibles de ser beneficiados superficialmente, sin necesidad de complejos sistemas de explotación minera (Rodríguez Vinceiro, 2003: 303).

- Evidencia en ellos de una actividad minera que se manifiesta a través de pequeñas trincheras y catas en las que están ausentes las huellas de barrenos y otros indicios de minería moderna. Ninguna de ellas ha sido excavada ni ha aportado evidencias directas e incuestionables de su cronología prehistórica, aunque se han recuperado en ellas los siguientes indicios que las pueden relacionar con la prehistoria: un fragmento de machacador sobre roca ultrabásica y una posible base de molturación realizada en grauvaca en las minas de Casacara, en Casabermeja (Rodríguez-Vinceiro et al., 1991: 76). Varios fragmentos de martillos recuperados

2 Gómez Ramos, P.: La tecnología de fundición de metales en la pre-y protohistoria de la Peninsula Ibérica. Tesis doctoral microfilmada presentada en 1996 en Univ. Autónoma de Madrid. en las cercanías de mineral en bruto machacado y cerámica a mano bruñida en las minas de la Peluca (Fernández-Rodríguez et al., 1992: 135); diversos fragmentos de material cerámico y lítico en la mina de Arroyo Teatinos (Fernández-Rodríguez et al., 1992: 136); restos de cerámica a mano en la mina Boticario II (Fernández-Rodríguez et al., 1992: 137); un machacador en la mina de Arroyo Zapateros (datos inéditos), y, por último, varias mazas de minero realizadas sobre diabasa en las minas del Cortijo de las Tormentas -datos inéditos-, todas ellas localizadas en el término municipal de Málaga.

- Existencia en los yacimientos arqueológicos de distintas pruebas de actividad metalúrgica, que en el caso de El Castillejo (Almogía) y de Cerro de Los Peñones y Colmenar abarcan toda la cadena productiva metalúrgica, desde el mineral hasta el objeto acabado.

Por tanto, no hay, hasta la fecha, evidencias directas de minería prehistórica en los Montes de Málaga, aunque sí indicios suficientes para proponer su existencia como hipótesis de trabajo y evaluar la pertinencia de dicha hipótesis utilizando, como evidencia indirecta, el método de isótopos de plomo, que permite correlacionar tanto el metal acabado como el resto de los elementos que intervienen en el proceso metalúrgico con las mineralizaciones de las que pudieron proceder. Este análisis se basa en la proporción de los cuatro isótopos del plomo $-{ }^{204} \mathrm{~Pb}$, ${ }^{206} \mathrm{~Pb},{ }^{207} \mathrm{~Pb}$ y ${ }^{208} \mathrm{~Pb}$ - presentes en los depósitos minerales y su correlación con las proporciones isotópicas de los restos arqueológicos. Los fundamentos del método en su aplicación a la arqueología han sido expuestos con suficiente precisión en distintas publicaciones (Stos-Gale, 1990; Budd et al., 1996; Gale y Stos-Gale, 1996; Hunt, 1998 y 2003; Ixer, 1999; Montero y Hunt, 2006; Pernicka, 2014) por lo que no resulta necesario referirlos aquí, simplemente señalaremos el hecho de que una vez que el mineral es depositado, su composición isotópica no se verá modificada en los subsiguientes procesos metalúrgicos - a excepción del reciclado y la mezcla de minerales- y por lo tanto constituye una especie 


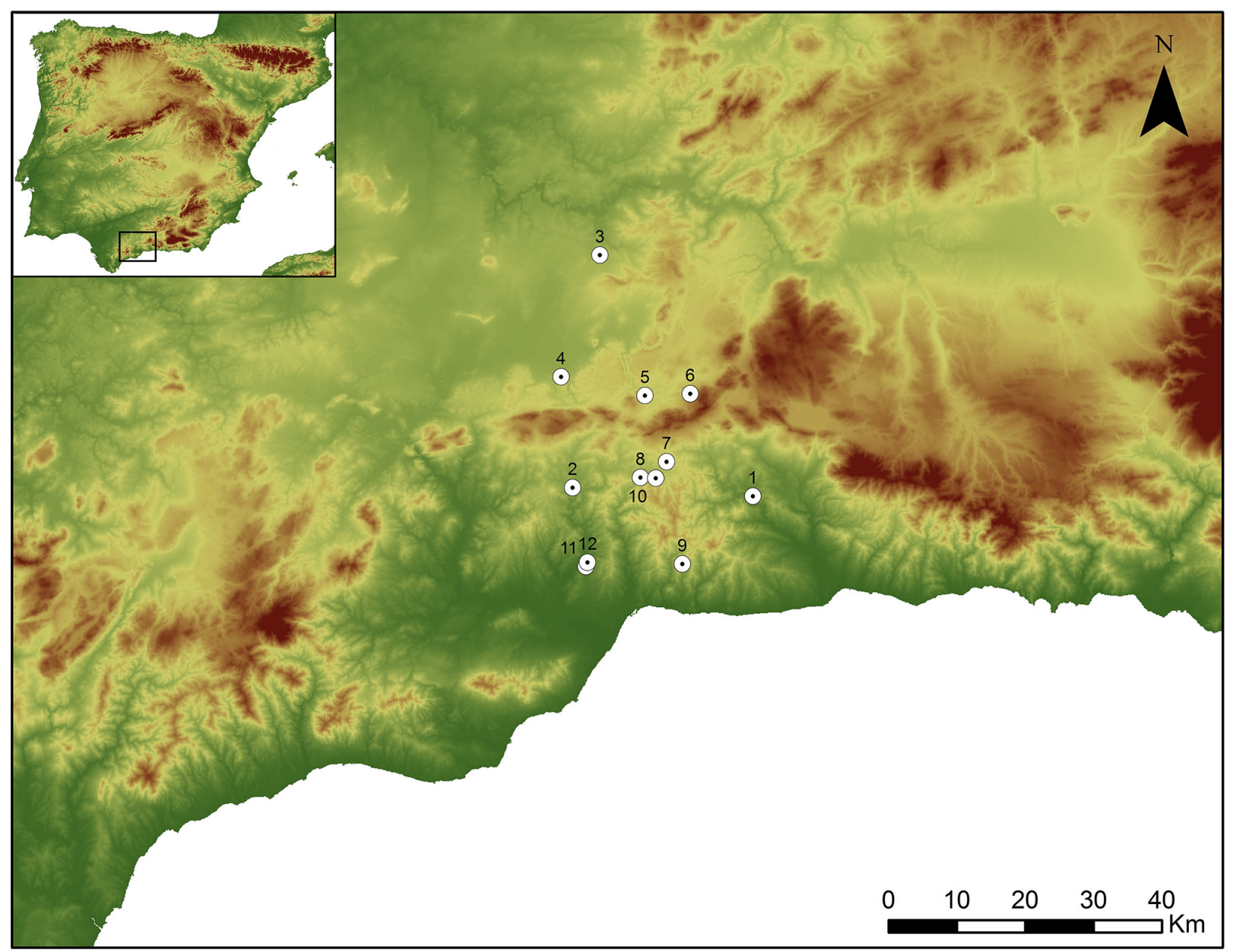

Fig. 1. Procedencia de los análisis de isótopos de plomo de la provincia de Málaga ( $A=$ asentamiento; $N=$ necrópolis; $M=$ mina): 1. Peña de Hierro (A); 2. El Castillejo (A); 3. Alcaide (N); 4. Marimacho (A); 5. Cortijo del Tardón (N); 6. Peñón del Oso (A); 7. Los Peñones (A); 8. Cerro García (A); 9. Olías (M); 10. Casacara (M); 11. Lagar de las Ánimas (M); 12. Arroyo Negrete (M).

de 'huella digital' de la mineralización. Por tanto, la comparación de la proporción isotópica de los restos arqueológicos y las muestras geológicas constituye, a día de hoy, el método más fiable para los estudios de procedencia. Este método puede acompañarse de un estudio de elementos traza, aunque esto no es siempre posible. En este caso, los análisis de composición elemental los realizamos mediante la técnica de fluorescencia de rayos $\mathrm{x}$ empleando un equipo portátil, lo que nos permite la realización de análisis de composición superficial de los restos arqueológicos sin necesidad de extracción de muestra.

\section{Datos analíticos}

Para contrastar la hipótesis de partida se han utilizado varios conjuntos de datos analíticos de distinta procedencia:

- Análisis de isótopos de plomo publicados de muestras procedentes de objetos arqueológicos de yacimientos del SE: Almizaraque, El Barranquete, Terrera Ventura y Murviedro (Montero-Ruiz y Murillo-Barroso, 2010; Stos-Gale et al., 1999; OXALID). 


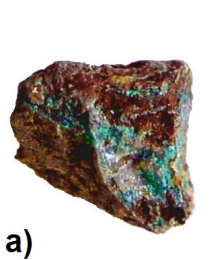

a)
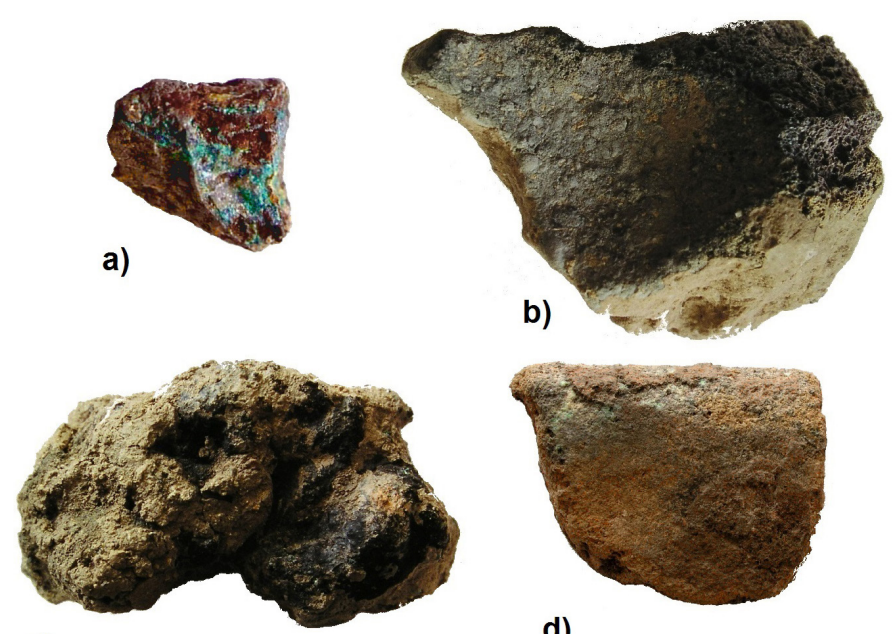

c) 0

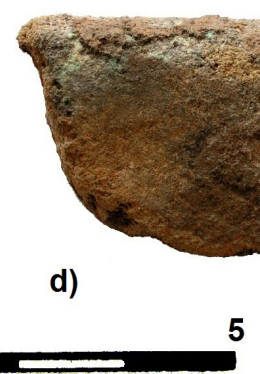

FIG. 2. Algunas de las muestras analizadas: a) mineral de cobre procedente de El Castillejo (Almogía, Málaga), sondeo de 1993, Corte 1, Nivel III; análisis de isótopos de plomo en la Fig. 4, n. ${ }^{\circ}$ de inv. EC-122; b) fragmento de crisol procedente de El Castillejo (Almogía, Málaga), sondeo de 1993, Corte 1, Nivel III; análisis XRF PA 11883 inédito: Fe: 2.70, Ni: nd, Cu: 0.27, Zn: nd, As: 0.11, Ag: nd, Sn: nd, Sb: nd, Au: -, Pb: 0.02, Bi: nd; c) fragmento de escoria procedente de El Castillejo (Almogía, Málaga), sondeo de 1993, Corte 1, Nivel V; análisis de isótopos de plomo en la Fig. 5, n. ${ }^{\circ}$ de inv. EC-113; d) fragmento de crisol procedente de Marimacho (Antequera, Málaga), excavación de 1997, Corte 1, Nivel 4; análisis pXRF cualitativo inédito: $P$ : nd, $S:$ nd, $C l: n d, K: n d$, Ca: nd, Ti: 0.1, Mn: tr, Fe: 1.9, Co: nd, Cu: 7.3, Zn:tr, As: tr, Ag: nd, Sn: nd, Sb: nd, Ba: nd, Pb: nd.

- Análisis de isótopos de plomo procedentes de las mineralizaciones del s de la Península Ibérica, en parte inéditos, aunque en su mayoría publicados: Sierra Morena, Valle de Los Pedroches-Alcudia (Hunt et al., 2012; Klein et al., 2009; Arboledas et al., 2006; Santos et al., 2004; Tornos and Chiarada, 2004); el sE (Graeser y Friedrich,
1970; Dayton y Dayton, 1986; Arribas Jr. y Tosdal, 1994; Stos-Gale et al., 1995, 1999; Klein et al., 2009; Montero-Ruiz y Murillo-Barroso, 2010); y el so (Marcoux, 1998; Stos-Gale et al., 1995; Hunt, 2003).

—Conjunto de 36 análisis de isótopos de plomo inéditos. 14 sobre muestras minerales tanto geológicas como recuperadas en contextos arqueológicos y 22 sobre restos arqueológicos de producción metalúrgica, procedentes de diversas localizaciones de la provincia de Málaga (Figs. 1 y 2).

Los análisis han podido realizarse gracias a una subvención concedida por la Consejería de Cultura de la Junta de Andalucía y han sido elaborados por el Servicio de Geocronología de la Universidad del País Vasco. A continuación, se presentan los resultados de las analíticas, realizadas sobre los siguientes materiales:

- 5 sobre muestras minerales procedentes de afloramientos cupríferos de los Montes de Málaga con aprovechamiento minero -Arroyo Negrete, Lagar de las Ánimas, Casacara y Olías-El Ángel- (Fig. 3).

- 9 sobre muestras minerales recuperadas en los distintos yacimientos arqueológicos de la zona de estudio -El Castillejo, Cerro García, Peña de Hierro y Cerro de Los Peñones- (Fig. 4).

- 22 obtenidos de restos arqueológicos -elementos de la cadena de producción y objetos acabados- procedentes también de los yacimientos ubicados en las Tierras de Antequera: asentamientos de El Castillejo, Cerro de los Peñones, Peñón del Oso y Marimacho y necrópolis de Alcaide y Cortijo de El Tardón -cf. apartado 6-.

\begin{tabular}{|l|l|c|c|c|c|c|c|}
\hline \multicolumn{1}{|c|}{ Mina } & Localidad & Inventario & $\mathbf{2 0 6} \mathrm{Pb} / \mathbf{2 0 4} \mathbf{P b}$ & $\mathbf{2 0 7} \mathbf{P b} / \mathbf{2 0 4} \mathrm{Pb}$ & $\mathbf{2 0 8 P b} \mathbf{2 0 4} \mathbf{P b}$ & $\mathbf{2 0 7} \mathrm{Pb} / \mathbf{2 0 6} \mathbf{P b}$ & $\mathbf{2 0 8} \mathrm{Pb} / \mathbf{2 0 6} \mathrm{Pb}$ \\
\hline Olías-El Ángel & Málaga & MO-1 & 18,724 & 15,665 & 39,029 & 0,83662 & 2,08441 \\
\hline Casacara & Colmenar & MC-1 & 18,546 & 15,646 & 38,640 & 0,84365 & 2,08343 \\
\hline Lagar de las Ánimas & Málaga & LA-1 & 19,234 & 15,690 & 38,690 & 0,81613 & 2,01251 \\
\hline Lagar de las Ánimas & Málaga & LA-2 & 19,117 & 15,714 & 38,812 & 0,82200 & 2,03023 \\
\hline Arroyo Negrete & Málaga & AN & 18,612 & 15,800 & 39,028 & 0,84891 & 2,09693 \\
\hline
\end{tabular}

FIG. 3. Análisis de isótopos de plomo de afloramientos cupriferos de Montes de Málaga. 


\begin{tabular}{|c|c|c|c|c|c|c|c|}
\hline Objeto & Inventario & Yacimiento & $206 \mathrm{~Pb} / 204 \mathrm{~Pb}$ & $207 \mathrm{~Pb} / 204 \mathrm{~Pb}$ & $208 \mathrm{~Pb} / 204 \mathrm{~Pb}$ & $207 \mathrm{~Pb} / 206 \mathrm{~Pb}$ & $208 \mathrm{~Pb} / 206 \mathrm{~Pb}$ \\
\hline Mineral $\mathrm{Cu}$ & EC-114 & El Castillejo & 18,484 & 15,657 & 38,652 & 0,84705 & 2,09113 \\
\hline Mineral $\mathrm{Cu}$ & EC-115 & El Castillejo & 20,132 & 15,764 & 38,745 & 0,78306 & 1,92460 \\
\hline Mineral Cu & EC-122 & El Castillejo & 18,645 & 15,656 & 38,638 & 0,83968 & 2,07228 \\
\hline Mineral Cu & EC-124 & El Castillejo & 20,099 & 15,769 & 38,857 & 0,78453 & 1,93323 \\
\hline Mineral $\mathrm{Cu}$ & CG-3 & Cerro García & 18,478 & 15,641 & 38,513 & 0,84645 & 2,08426 \\
\hline Mineral $\mathrm{Cu}$ & PH-2 & Peńa de Hierro & 18,654 & 15,676 & 38,924 & 0,84035 & 2,08656 \\
\hline Mineral Cu & $\mathrm{CP}-7$ & Los Peñones & 18,455 & 15,627 & 38,377 & 0,84679 & 2,07957 \\
\hline Mineral $\mathrm{Cu}$ & $\mathrm{CP}-8$ & Los Peñones & 18,900 & 15,679 & 38,832 & 0,82958 & 2,05455 \\
\hline Mineral $\mathrm{Cu}$ & СР-9 & Los Peñones & 18,789 & 15,669 & 38,714 & 0,83396 & 2,06050 \\
\hline
\end{tabular}

Fig. 4. Análisis de isótopos de plomo de minerales procedentes de yacimientos arqueológicos de Tierras de Antequera.

- Datos procedentes de actividades arqueológicas preventivas aportados por excavaciones realizadas por la empresa Taller de Investigaciones Arqueológicas SL: dos analíticas procedentes de El Silillo y una de El Comandante, ambos yacimientos de encuentran en el término municipal de Antequera (Fernández-Rodríguez et al., 2014a).

\section{Fuentes de aprovisionamiento: el Maláguide}

De entre las fuentes potenciales de suministro de recursos cupríferos que se disponen alrededor de las Tierras de Antequera, la comarca de Los Montes de Málaga es, a la vez, la más cercana y la más desconocida. La unidad topográfica de Los Montes de

\begin{tabular}{|c|c|c|c|c|c|c|c|c|c|c|c|c|c|c|c|c|c|c|c|}
\hline Rd & ID & Procedencia & $\mathbf{P}$ & $S$ & $\mathrm{Cl}$ & K & $\mathrm{Ca}$ & $\mathrm{Ti}$ & Mn & $\mathrm{Fe}$ & $\mathrm{Co}_{0}$ & $\mathrm{Cu}$ & $\mathrm{Zn}$ & As & $\mathrm{Ag}$ & Sn & $\mathrm{Sb}$ & $\mathrm{Ba}$ & $\mathrm{Pb}$ \\
\hline$\# 2$ & 21 & Casacara (M) & 2.8 & 0.5 & 0.2 & 0.3 & tr & $\operatorname{tr}$ & $\operatorname{tr}$ & 0.4 & nd & 9.5 & 0.1 & tr & nd & nd & nd & nd & $\mathrm{tr}$ \\
\hline$\# 3$ & 21 & Casacara (M) & 1.2 & 0.5 & $\operatorname{tr}$ & 0.1 & nd & tr & tr & 0.3 & tr & 6.5 & 0.1 & tr & nd & nd & nd & nd & $\operatorname{tr}$ \\
\hline$\# 4$ & 32.10 & Casacara (M) & 3.9 & 29.0 & nd & nd & 0.1 & nd & tr & 45.5 & tr & 21.1 & 0.1 & tr & nd & nd & nd & nd & nd \\
\hline$\# 5$ & 32.10 & Casacara (M) & 6.8 & 27.2 & 0.3 & nd & 0.7 & nd & 0.8 & 37.9 & 0.2 & 25.6 & $\operatorname{tr}$ & tr & nd & nd & nd & nd & nd \\
\hline$\# 6$ & 20.1 & Casacara (M) & 6.2 & 1.7 & 0.2 & 0.8 & 0.3 & 0.1 & tr & 31.2 & 0.0 & 28.7 & tr & tr & nd & nd & nd & nd & tr \\
\hline$\# 7$ & 20.1 & Casacara (M) & 11.1 & 2.3 & 0.4 & 0.4 & 0.4 & 0.1 & tr & 34.6 & 0.1 & 45.6 & tr & tr & nd & nd & nd & nd & tr \\
\hline$\# 8$ & 20.2 & Casacara (M) & 8.0 & 8.5 & 0.5 & 1.3 & 1.9 & tr & 0.1 & 15.7 & tr & 63.2 & 0.2 & 0.1 & nd & nd & nd & nd & $\operatorname{tr}$ \\
\hline \#9 & 20.2 & Casacara (M) & 9.0 & 2.7 & 0.4 & 2.6 & 1.4 & tr & 0.2 & 12.9 & tr & 70.0 & 0.2 & tr & nd & nd & nd & nd & tr \\
\hline$\# 10$ & 19.2 & Casacara (м) & 5.9 & 1.4 & 0.3 & 2.2 & 0.6 & 0.2 & 1.2 & 8.3 & 0.2 & 43.7 & 0.6 & tr & nd & nd & nd & nd & tr \\
\hline$\# 11$ & 10.1 & Casacara (M) & nd & 1.0 & 0.1 & 0.2 & 19.5 & tr & tr & tr & tr & 16.9 & 0.9 & 1.4 & tr & nd & tr & 0.5 & 0.1 \\
\hline$\# 12$ & 10.1 & Casacara (M) & nd & 2.9 & 0.3 & 0.5 & 53.5 & tr & 0.5 & 0.1 & 0.2 & 32.9 & 3.3 & 4.5 & $\operatorname{tr}$ & nd & $\mathrm{tr}$ & 0.7 & 0.1 \\
\hline$\# 14$ & 10.2 & Casacara (M) & nd & 3.9 & 0.3 & 0.4 & 42.1 & 0.1 & 0.1 & 0.1 & tr & 42.2 & 4.1 & 5.6 & tr & nd & tr & 0.4 & 0.1 \\
\hline$\# 15$ & 30.5 & Lagar de los Huescas (M) & 5.8 & 1.6 & 0.4 & 6.7 & 0.3 & 0.6 & tr & 1.0 & nd & 39.0 & $\operatorname{tr}$ & tr & nd & nd & tr & nd & nd \\
\hline$\# 16$ & 3.1 & Lagar de los Huescas (M) & nd & nd & nd & 0.5 & nd & tr & tr & 1.8 & nd & 1.6 & nd & tr & nd & tr & nd & nd & nd \\
\hline$\# 17$ & 1 & Caserón Palomeras (M) & 10.8 & 19.1 & 0.6 & 0.9 & 0.3 & 0.1 & tr & 3.7 & nd & 24.1 & 39.7 & nd & nd & nd & nd & nd & 0.2 \\
\hline$\# 18$ & 1 & Caserón Palomeras (M) & 9.1 & 17.9 & 0.6 & 0.9 & 0.3 & 0.1 & tr & 3.9 & nd & 27.7 & 38.8 & tr & nd & tr & nd & nd & 0.2 \\
\hline$\# 19$ & 34 & Lagar de las Ánimas (M) & 10.8 & 4.0 & 0.7 & 1.4 & 0.3 & 0.2 & tr & 0.6 & nd & 81.7 & tr & nd & tr & tr & nd & nd & tr \\
\hline$\# 20$ & 34 & Lagar de las Ánimas (M) & 12.1 & 3.7 & 0.7 & 2.9 & 1.5 & 0.5 & tr & 1.1 & nd & 80.3 & tr & nd & tr & nd & nd & nd & tr \\
\hline$\# 21$ & 33.8 & Lagar de las Ánimas (M) & 12.1 & 3.9 & 0.6 & 3.0 & 0.3 & 0.6 & tr & 0.4 & nd & 78.4 & 0.1 & nd & tr & $\operatorname{tr}$ & nd & nd & tr \\
\hline$\# 29$ & 21.1 & Peñas de Cabreras (AF) & nd & 1.8 & tr & 1.6 & 0.9 & 0.3 & 0.5 & tr & tr & 3.7 & 0.3 & 0.2 & tr & nd & tr & 0.4 & tr \\
\hline$\# 32$ & 5.1 & Santopitar (м) & nd & 28.4 & 0.3 & nd & 0.1 & nd & tr & 44.9 & nd & 15.4 & $\operatorname{tr}$ & tr & tr & nd & nd & nd & nd \\
\hline$\# 33$ & 5.2 & Santopitar (м) & 5.0 & 1.8 & 0.3 & 0.5 & 0.8 & 0.1 & 11.9 & 10.9 & 2.3 & 35.4 & 1.1 & tr & nd & nd & nd & nd & 0.1 \\
\hline$\# 34$ & 18.1 & Los Bravos (M) & 4.5 & 0.8 & 0.2 & 0.3 & 1.7 & 0.2 & tr & 5.5 & nd & 23.9 & $\operatorname{tr}$ & tr & nd & nd & nd & nd & tr \\
\hline$\# 35$ & 18.2 & Los Bravos (M) & 3.4 & 0.6 & tr & 0.5 & 2.3 & 0.2 & tr & 4.8 & nd & 9.6 & tr & tr & nd & nd & nd & nd & tr \\
\hline$\# 36$ & 5.6 & El Ángel (M) & 6.6 & 1.2 & 0.3 & 5.9 & 0.2 & 0.9 & tr & 0.8 & nd & 32.8 & nd & tr & nd & nd & nd & nd & nd \\
\hline$\# 37$ & 28 & El Ángel (M) & nd & 0.6 & 0.1 & nd & tr & tr & 0.1 & 1.7 & tr & 2.3 & nd & 0.1 & nd & nd & nd & nd & tr \\
\hline
\end{tabular}




\begin{tabular}{|c|c|c|c|c|c|c|c|c|c|c|c|c|c|c|c|c|c|c|c|}
\hline Rd & ID & Procedencia & $\mathbf{P}$ & $S$ & $\mathrm{Cl}$ & K & $\mathrm{Ca}$ & $\mathrm{Ti}$ & Mn & $\mathrm{Fe}$ & Co & $\mathrm{Cu}$ & $\mathrm{Zn}$ & As & $\mathrm{Ag}$ & Sn & Sb & $\mathrm{Ba}$ & $\mathrm{Pb}$ \\
\hline$\# 38$ & 4 & Arroyo Negrete (м) & nd & 0.7 & nd & 1.5 & 0.7 & 0.1 & nd & 0.6 & nd & 2.2 & nd & $\operatorname{tr}$ & nd & nd & nd & nd & tr \\
\hline$\# 39$ & 15.1 & Arroyo Matamoros (M) & 3.0 & 4.0 & 0.3 & 1.0 & 2.6 & 0.1 & $\operatorname{tr}$ & 0.6 & tr & 15.1 & 0.1 & $\operatorname{tr}$ & nd & nd & nd & nd & nd \\
\hline$\# 40$ & 15.1 & Arroyo Matamoros (M) & 2.1 & 2.8 & 0.2 & 1.6 & 1.9 & 0.2 & 0.3 & 1.4 & $\operatorname{tr}$ & 12.5 & 0.1 & $\operatorname{tr}$ & nd & nd & nd & nd & tr \\
\hline$\# 41$ & 29 & Cerro García (As) & 11.1 & 17.7 & 0.7 & 0.6 & 0.2 & 0.2 & 0.1 & 4.3 & nd & 51.6 & nd & $\operatorname{tr}$ & nd & nd & nd & nd & nd \\
\hline$\# 42$ & 27 & Cerro Coronado (м) & 1.5 & 3.0 & 0.5 & 4.9 & 2.4 & 0.7 & 0.2 & 22.3 & nd & 52.2 & 0.2 & $\operatorname{tr}$ & nd & nd & tr & nd & tr \\
\hline$\# 43$ & 25 & Peńones (As) & nd & nd & nd & nd & 0.2 & nd & nd & 34.5 & nd & 11.9 & nd & $\operatorname{tr}$ & nd & nd & nd & nd & nd \\
\hline$\# 45$ & 26 & Peńa de Hierro (AS) & 13.0 & 3.4 & 0.9 & 0.3 & 0.3 & 0.2 & 0.1 & 17.6 & 0.1 & 64.0 & 1.0 & nd & nd & nd & nd & nd & tr \\
\hline
\end{tabular}

Fig. 5. Análisis pXRF cualitativos de muestras minerales de Montes de Málaga. Resultados en \% en peso. No se presentan normalizados, la diferencia a 100 la componen elementos ligeros. Los análisis que comparten identificación (ID) corresponden a una misma muestra. $N d=$ no detectado; $\operatorname{tr}=$ trazas. $(M)=$ mina; $(A F)=$ afloramiento; $(A S)=$ asentamiento.

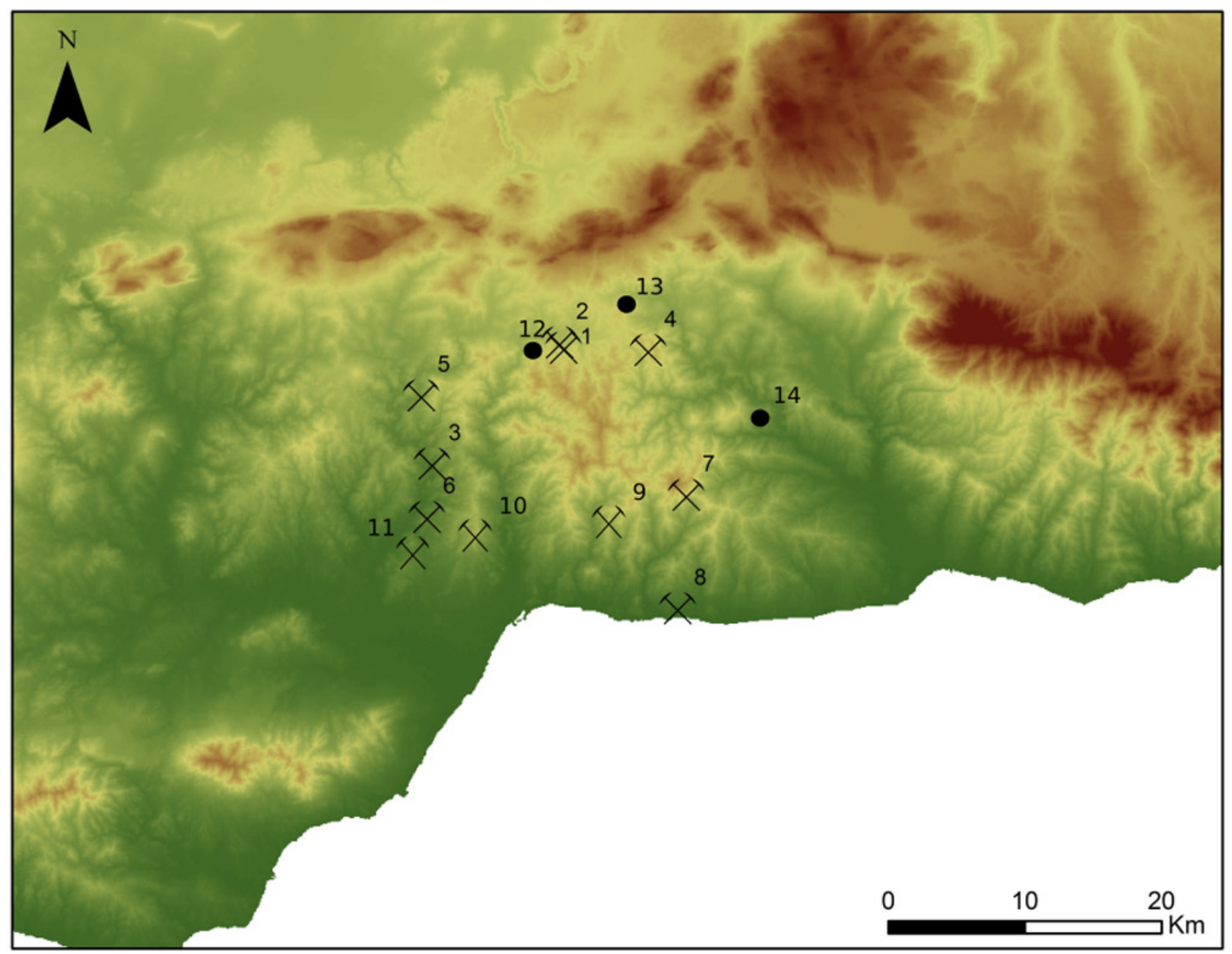

FIG. 6. Localización de las muestras minerales de Montes de Málaga analizadas mediante pXRF cualitativos: 1) Casacara; 2) Peñas de Cabrera; 3) Arroyo Matamoros; 4) Caserón de las Palomeras; 5) Lagar de los Huescas; 6) Arroyo Negrete; 7) Santopitar; 8) Los Bravos; 9) El Ángel; 10) Cerro Coronado; 11) Lagar de las Ánimas; 12) Cerro García; 13) Peñones; 14) Peña de Hierro.

Málaga forma parte del Complejo Maláguide, del que constituye su principal afloramiento. No obstante, su distribución espacial es bastante irregular (Mérida, 1997), pues se extiende por numerosos puntos de 
las Cordilleras Béticas, sobre todo en la provincia de Málaga -donde aflora como retazos discontinuos y jalonados por formaciones alpujárrides o afines-, aunque cuenta también con afloramientos importantes entre las depresiones de Granada y Guadix, en la zona nororiental de la provincia de Almería y en parte de la de Murcia (Mapa Geológico de España, serie MAGNA, hojas 974, 952, 975).

Los recursos minerales cupríferos no son especialmente abundantes en el Maláguide, no obstante, se encuentran pequeñas áreas mineralizadas diseminadas por toda su extensión, ofreciendo recursos que, si bien no son aprovechables desde criterios económicos actuales, sí pueden serlo para una economía de subsistencia y a pequeńa escala. Estos se alojan en distintas formaciones de su estratigrafía, que se compone de una serie paleozoica y una cobertera mesozoica que se apoya discordantemente sobre ella (Romero, 2003). En la serie paleozoica los minerales cupríferos tienden a concentrarse en los filones de cuarzo que rompen los planos de estratificación impregnando las filitas infrasilúricas y las filitas y grauvacas devónico-carboníferas, mientras que en la cobertera son las areniscas permotriásicas las que contienen los minerales de cobre, esta vez de origen detrítico. Estas características del Complejo Maláguide son muy homogéneas en todos los ámbitos en los que aflora.

En trabajos anteriores (Rodríguez Vinceiro, 2003), a los que nos remitimos, se han expuesto las características de los distintos tipos de mineralizaciones de cobre presentes en el Complejo Maláguide. En esta ocasión, por el contrario, no abundaremos en estas explicaciones, sino que aportamos una serie de 34 análisis pXRF cualitativos de muestras minerales - malaquita y azurita en todos los casosde los Montes de Málaga que, junto con los análisis de isótopos de plomo que también se dan a conocer en este trabajo, intentan avanzar en su caracterización (Figs. 5 y 6 ).

En relación a ellos, y estando pendiente aún un estudio que los compare con los análisis XRF de piezas metálicas de Málaga realizados hace algunos ańos por Rovira en el marco del Proyecto de Investigación Arqueometalúrgica de la Península

(C) Universidad de Salamanca
Ibérica y por Bartelheim en el Lehrstuhl für Archäometallurgie (Freiburg, Alemania), que permanecen inéditos, podemos destacar la escasez de arsénico en los minerales maláguides analizados, con excepción de dos muestras de las minas de Casacara que han proporcionado valores de As en torno al 5\%.

\section{Metalurgia en las Tierras de Antequera: los restos materiales}

La cantidad de objetos metálicos recuperados en las Tierras de Antequera no tiene la importancia en número de elementos y peso que se constata en otras zonas del se y so peninsular, aunque sí alcanza puntualmente en algunos yacimientos una presencia muy destacable.

Los primeros objetos metálicos y restos relacionados con la producción metalúrgica documentados en este ámbito pueden remontarse hasta mediados del III milenio AC, procediendo de los siguientes yacimientos (Fig. 7):

- Tajillo del Moro (Casabermeja): se trata de un sepulcro megalítico de corredor ubicado en las laderas septentrionales de los Montes de Málaga, en el contacto con el flysch de Colmenar, en las cercanías de los asentamientos de Cerro García y Los Peñones, de la estación rupestre de Peñas de Cabrera y las minas de cobre de Casacara. Fue excavado por la Universidad de Málaga en 1979 y proporcionó una única pieza de metal: un hacha de cobre de $260 \mathrm{~g}$ de peso que, dado el carácter colectivo del enterramiento y su estado de remoción, no ha sido posible asociar a restos humanos concretos. Carece de fechas radiocarbónicas, pero el conjunto del material arqueológico, muy homogéneo en su composición, llevó a sus excavadores a postular su pertenencia a una fase de Cobre Antiguo, que cronológicamente sitúan en la segunda mitad del tercer milenio (Ferrer et al., 1980).

- El Silillo (Antequera): es un yacimiento de los llamados de 'campos de silos', situado en el área $\mathrm{N}$ de la vega de Antequera, detectado y excavado, 
tan solo en la porción afectada -un 10\% aproximadamente-, en el curso de las actividades preventivas destinadas a paliar las afecciones causadas por las obras de construcción de la autovía A-45 (Fernández Rodríguez et al., 2014a). Varias de sus subestructuras han proporcionado elementos relacionados con la metalurgia, tanto productos acabados como elementos de producción. Consta también de fechas de C14. Procederemos a revisar estas evidencias con más detalle:

- Subestructura 29: se recuperó en ella una pieza cerámica de tendencia cilíndrica, con restos de rubefacción, que se caracterizó como tobera dada su similitud con las documentadas en el llamado barrio metalúrgico de Valencina de la Concepción (Nocete et al., 2008: 728). No obstante, su relación con las actividades metalúrgicas no está comprobada ya que los análisis de composición elemental realizados recientemente muestran que no existen, en las partes del objeto que se pudieron analizar, restos de elementos metálicos relacionados con la producción de cobre. Tampoco se observan concreciones escoriáceas o vitrificación en ninguno de sus

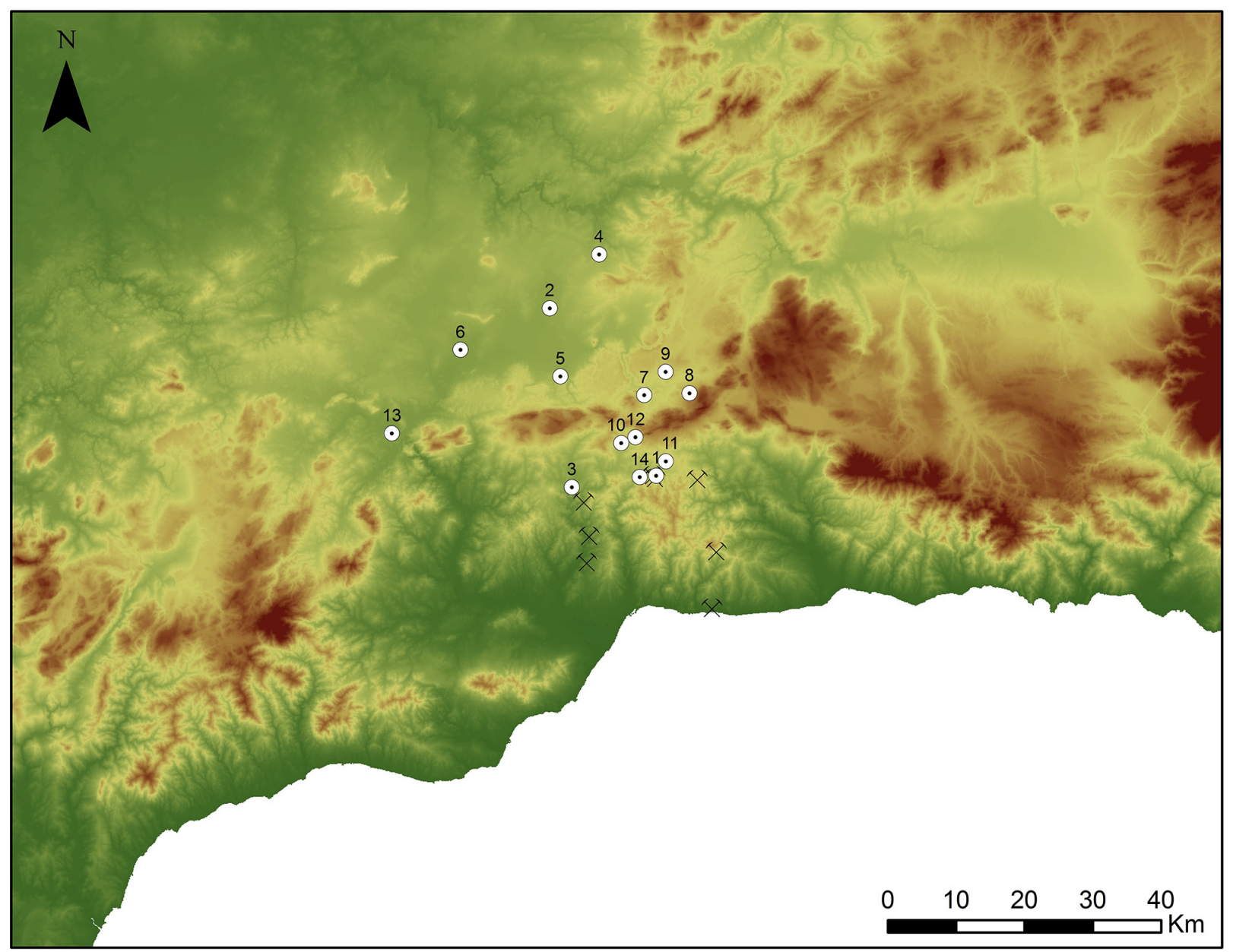

FIG. 7. Restos metalúrgicos en yacimientos del III milenio en Tierras de Antequera ( $A=$ asentamiento y $N=$ necrópolis): 1. Tajillo del Moro (N); 2. El Silillo (A); 3. El Castillejo (A); 4. Alcaide (N); 5. Marimacho (A); 6. Cerro del Comandante (A); 7. Cortijo del Tardón (N); 8. Peñón del Oso (A); 9. Peñón de Solis (A); 10. Cauche el Viejo (A); 11. Los Peñones (A); 12. Cerro Ajorca (?); 13. Las Aguilillas-El Parque (N); 14. Cerro García (A). 
extremos ni una elevada alteración térmica de la pasta cerámica. Del mismo modo, el diámetro interno de la pieza $-5 \mathrm{~cm}$ - resulta extremadamente ancho para un uso eficiente como tobera. Estudios experimentales han mostrado que los diámetros internos de las boquillas de soplado deben tener entre 5 y 10 $\mathrm{mm}$-como es el caso de las documentadas en el yacimiento de Las Pilas, por poner un ejemplo (Murillo Barroso et al., 2017)-; las toberas acopladas a fuelles entre 15 y $35 \mathrm{~mm}$; y solo las toberas u oquedades de las chimeneas de hornos para una ventilación natural, algo que no se ha documentado en el Calcolítico de la Península Ibérica, entre 50-100 mm (Rehder, 1994: 348), por lo habría que buscar otras posibles funcionalidades distintas a las metalúrgicas para esta pieza en cuestión.

- Subestructura 20: proporcionó un posible molde o lingotera realizado en piedra (calcarenita), de planta elíptica, con una gota de cobre adherida a su superficie en la zona cercana al borde. El análisis de la gota determinó que se trata de cobre arsenicado $-1,5 \%$ As aprox.-. Morfológicamente, el recipiente comparte características con crisoles procedentes de Malagón (Arribas et al., 1978) y Valencina (Nocete et al., 2008: 729), aunque todos estos ejemplares están realizados en arcilla. El hecho de que esta pieza esté elaborada en piedra, carezca de adherencias escoriáceas y de evidencias de haber estado expuesta a altas temperaturas, así como la gota de cobre metálico que documentamos en el borde, nos hace inclinarnos más por caracterizarla como molde.

- Subestructura 3: su excavación deparó 2 hojas metálicas, una de ellas dentada (sierra, $1 \mathrm{~g}$ ) y otra ligeramente curvada (posible hoz, $3 \mathrm{~g}$ ).

- Fechas radiocarbónicas: las tres dataciones radiométricas procesadas, obtenidas a partir de madera carbonizada, proceden del área $\mathrm{N}$ del yacimiento: Subestructura 12 (Ua-35080, $3775 \pm 40$ BP, 2340-2110 cal AC $2 \sigma)$, subestructura $16(\mathrm{Ua}-35081,3980 \pm 40$
BP, 2340-2110 cal AC 2б) y subestructura 20 (Ua-35082, $3965 \pm 40$ вр, 2580-2340 cal AC $2 \sigma$ ), procediendo dos de ellas, pues, del ámbito del yacimiento que ha proporcionado los restos de actividad metalúrgica, aunque no de subestructuras directamente relacionadas con ellas, y otra (n. $\left.{ }^{\circ} 20\right)$ de la que contenía el molde/lingotera. Las tres pueden encuadrarse en la segunda mitad del III milenio, por lo que tendríamos fechadas dichas actividades con suficiente precisión.

- ElCastillejo(Almogía): ElCastillejo es el principal referente para el estudio de la metalurgia prehistórica en Málaga. Su conocimiento procede de las cuatro campañas de prospección superficial realizadas en el marco del proyecto arqueometalúrgico de la provincia de Málaga entre 1989 y 1992 y una de prospección con sondeo desarrollada en 1993 que confirmó, en una superficie de sólo $18 \mathrm{~m}^{2}$, las hipótesis formuladas sobre el material de superficie recogido previamente y permitió obtener una secuencia estratigráfica, datada radiocarbónicamente, en la que contextualizar la producción metalúrgica del yacimiento. Su secuencia de ocupación es, hasta ahora, casi monofásica, al constar de una ocupación centrada en el III milenio -GrA20661, $3980 \pm 80$ BP, 2856-2210 cal AC 20- y -GrA20691, $4085 \pm$

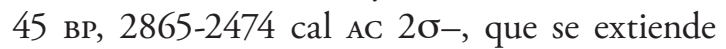
por las distintas terrazas del cerro, y una ocupación esporádica del Bronce Final que, aunque parece haber alterado solo débilmente el asentamiento calcolítico, reutiliza parte de su necrópolis mediante el procedimiento, ya documentado en numerosos yacimientos, de limpiar o despejar su interior para realizar las nuevas deposiciones. No se puede descartar, tampoco, la existencia de una primera fase en el poblado, intuida a partir de algunas subestructuras tipo silo detectadas en excavación, aunque no excavadas. Por lo que respecta a la metalurgia, y aunque el yacimiento ya fue dado a conocer en otros foros (Rodríguez Vinceiro y Fernández Rodríguez, 1998), realizaremos aquí una rápida síntesis de los resultados 
obtenidos en aquellas campañas, pues desde entonces el yacimiento no ha sido objeto de nuevas investigaciones sobre el terreno. En primer lugar, el yacimiento proporcionó 44 elementos relacionados con la metalurgia del cobre -objetos o fragmentos de objetos, gotas y escorias-, con un peso total de $808 \mathrm{~g}$, procediendo 31 de ellos de superficie y 13 del sondeo estratigráfico. También se recuperaron 19 restos minerales de cobre $-49 \mathrm{~g}-$, de los cuales 10 pertenecen a superficie y 9 a la estratigrafía y 3 fragmentos de vasija-horno procedentes de estratigrafía. Es, por tanto, el único yacimiento malagueño en el que se registra, en estratigrafía, todas las fases del proceso de producción metalúrgico.

- Necrópolis de Alcaide (Antequera): está considerado uno de los yacimientos más relevantes de la Prehistoria Reciente de la provincia de Málaga (Marqués y Aguado, 2012). Consta de 21 sepulcros de corredor y dos fosas de enterramiento excavados siempre en el substrato rocoso con un dilatado periodo de uso. Los sepulcros relacionados con el III milenio que han proporcionado elementos metálicos son los siguientes:

- Sepulcro n.o 21: durante la campaña de excavaciones de 1990 realizada por la Univ. de Málaga se recuperó en este sepulcro un pequeño escoplo con filo a doble bisel $-1,7$ g-, cuyo material asociado ayudó a datar su uso durante un Cobre precampaniforme ${ }^{3}$, aunque no contamos con fechas absolutas para esta cueva.

- Sepulcro n. ${ }^{\circ}$ 7: este sepulcro fue excavado por Giménez Reyna a mediados del s. xx y posteriormente objeto de una segunda intervención por la Universidad de Málaga. De las primeras excavaciones tenemos poca información contextual, habiendo proporcionado, junto al resto del material que publica Leisner (1965), una punta de cobre triangular. La excavación de la Universidad de Málaga recuperó además, en el corredor descubierto del sepulcro, una masa metálica o posible

3 Com. pers. de I. Marqués. lingote de cobre de $20 \mathrm{~g}$ de peso que confirma la frecuente aparición en este tipo de contexto de fragmentos de minerales y otras materias primas (Aguayo y García, 2006). Carece de dataciones absolutas y ha sido clasificada como perteneciente a la Edad del Cobre con campaniforme por sus excavadores ${ }^{4}$.

- Sepulcro n. ${ }^{\circ}$ 11: excavado igualmente por Giménez Reyna, carece de una documentación detallada, citándose como único objeto metálico una punta de palmela (Berdichewsky, 1964; Leisner, 1965).

- Sepulcro n. ${ }^{\circ}$ 19: excavado por la Univ. de Málaga (Baldomero et al., 1988; Marqués et al., 1990), ha proporcionado un puñal de lengüeta y la presencia de algún fragmento de cerámica campaniforme procedentes del mismo nivel de enterramiento. La datación absoluta disponible -GrN-16062, $4030 \pm 110$ BP, 2889-2229 cal AC 2б- sitúa el sepulcro hacia mediados del III milenio, fechando además la más temprana presencia de campaniforme en ambiente funerario de la provincia. Esta fecha estaría dentro de la normalidad al ser similar a las más tempranas conocidas tanto para el SE como para el SO (Ríos et al., 2011-12).

- Sepulcro n. ${ }^{\circ}$ 20: fue también excavado en 1990 por la Univ. de Málaga, encontrándose intacto. Contenía, además de un abundante nivel de enterramiento y diversos elementos de ajuar, 1 fragmento de cerámica campaniforme y, como el sepulcro n. ${ }^{\circ} 7,1$ gota de cobre -en este caso de solo $1 \mathrm{~g}$ de peso- encontrada en la cámara principal, que nuevamente hemos de interpretar como un elemento depositado intencionadamente con fines rituales.

- Marimacho (Antequera): asentamiento cercano a los sepulcros megalíticos de Menga y Viera, cuyas referencias iniciales proceden de estudios de materiales de superficie publicados en 1977

4 Com. pers. de I. Marqués. 
(Leiva et al., 1977) y 1987 (Ferrer et al., 1987) y cuya primera excavación, vinculada a una actividad de urgencia, se realizó en 1997 (Marqués et al., 2004) y la segunda y última hasta ahora se llevó a cabo en 2014 por idénticos motivos (García-González et al., 2014). Consta de varias fases de ocupación prehistórica, la primera de las cuales podría datarse a finales del IV milenio cal ANE, prolongándose durante el III milenio con evidencias de distintas subestructuras negativas de las comúnmente denominadas 'silos' $\mathrm{y}$ un foso para el que se propone una función delimitadora del asentamiento. Asociado a esta fase de silos se recuperó en la intervención de 1997 un fragmento de crisol con restos adheridos. Una segunda fase de ocupación, definida como de Cobre Campaniforme y que ha sido documentada hasta ahora solo mediante estratos erosivos, amortizaría las estructuras siliformes y respondería a patrones de asentamiento propios de momentos avanzados del III milenio. Esta fase aportó 3 objetos de metal: punzón-espátula, escoplo y amorfo.

- Cerro de El Comandante (Antequera): enclavado en la vega de Antequera, se trata nuevamente de un yacimiento detectado y excavado parcialmente gracias a una actividad arqueológica de carácter preventivo. Se compone de subestructuras de tipo silo asociadas a, al menos, un enterramiento colectivo de tipo hipogeico. El material metálico recuperado consiste en una punta Palmela de superficie que no se puede asociar con seguridad ni a la necrópolis ni las estructuras tipo silo. Durante el proceso de excavación se recogieron muestras para datación absoluta que se encuentran actualmente en proceso (Fernández-Rodríguez et al., 2014b).

- Cortijo de El Tardón (Antequera): se trata de una necrópolis situada en el Trias de Antequera, a poca distancia de los asentamientos de Peñón del Oso y Peñón de Solís. Está compuesta por dos estructuras que, aunque aparentan ser dolménicas, no están constituidas por alineaciones ortostáticas, sino que se trata de una formación rocosa natural, un flysch de calizas nummulíticas que afloran verticalmente en el terreno y que han sido utilizadas a modo de ortostatos para construir dos estructuras sepulcrales diferentes, perfectamente delimitadas y distantes $4 \mathrm{~m}$ entre sí (Fernández-Ruiz et al., 1997). De las dos estructuras solo el denominado Sepulcro в se fecha en el iII milenio, siendo las más antigua de las dos. Está fechada radiocarbónicamente en los últimos siglos del III milenio -GrN-16066, $3745 \pm 25$ вP, 2272-2039 cal aC 2б-. Proporcionó un ajuar metálico típico campaniforme: 1 hacha plana, 1 puñal de lengüeta, 1 punta Palmela y 1 punzón.

- Peñón del Oso (Villanueva del Rosario): asentamiento situado sobre una plataforma calcárea que se eleva sobre el valle del Guadalhorce, cuya vía de penetración domina, a la vez que posee un buen control visual de los importantes pasos de la Fresneda y las Pedrizas. Carece de fechas absolutas, aunque tanto los trabajos realizados sobre su material de superficie (Morales et al., 1986) como los del sondeo realizado por motivos de urgencia en 1985 (Moreno, 1987) encuadran su fase prehistórica de ocupación en un Cobre Tardío y Final, para el que se ofrecen fechas que irían al comienzo del in milenio. Posee objetos acabados y restos del proceso productivo - gotas de cobre y escorias-, aunque estos últimos proceden todos de superficie. El análisis elemental de los objetos y las gotas revela una composición similar de cobre arsenicado, mientras que las escorias no han sido aún analizadas. La existencia de una fase de ocupación tardorromana que podría ser responsable de dichas escorias y la distancia del yacimiento a los recursos metalíferos -unos accidentados $18 \mathrm{~km}$ que tendrían que sortear la barrera montañosa que suponen las sierras del Jobo y los Camarolosson argumentos que dificultan, a priori, la consideración de Peñón del Oso como un poblado que practique el beneficio directo de las menas cupríferas maláguides.

- Peñón de Solís (Villanueva del Rosario): yacimiento situado sobre una pequeña muela calcárea en el curso alto del río Guadalhorce. Su 
ocupación prehistórica está muy enmascarada, como en el caso del Peñón del Oso, por un hábitat tardorromano, no habiendo sido posible, a través de prospección superficial, caracterizar el yacimiento prehistórico. Tan solo conocemos de él, junto a algún material cerámico, 1 punta Palmela procedente de colección particular (Rodríguez-Vinceiro y Fernández-Rodríguez, 1998).

- Cauche el Viejo (Antequera): este asentamiento, que cuenta con una fase de subestructuras de tipo silo del Cobre Antiguo y otra posterior de Cobre con campaniforme, a mbas mal conocidas debido a las afecciones que provocaría el ulterior asentamiento romano de Aratispi, proporcionó, entre el material de superficie, una punta Palmela que, aunque carece lógicamente de información contextual, podríamos relacionar con este momento (Perdiguero, 1989-90 y 1995).

- Los Peñones (Colmenar): asentamiento emplazado sobre uno de los klippes sedimentarios que, de forma caótica, se encuentran inmersos en el flysch. Su posición estratégica domina el corredor del Campo de Cámara tanto hacia el $s$-enfrentado a Cerro García-, como hacia el N, de cara a las sierras calizas subbéticas que lo separan de la vega de Antequera -sierras del Jobo, Co, las Cabras y los Camarolos-. No ha sido excavado, pero ha proporcionado, además de 1 punta Palmela, 1 filo de hacha, 1 remache y 1 amorfo no tipologable, las siguientes evidencias de actividad metalúrgica: un fragmento de vasija de reducción cuyo análisis por fluorescencia de rayos $\mathrm{x}$ reveló un contenido en arsénico solo justificable a través de las absorciones sufridas durante el proceso de reducción, 3 fragmentos de mineral de cobre -malaquita sobre cuarzo de procedencia maláguide- y 1 gota de cobre. Actividades clandestinas extrajeron también del yacimiento 1 hacha plana de $312 \mathrm{~g}$ de peso (Rodríguez-Vinceiro et al., 1992).

- Cerro Ajorca (Casabermeja): este yacimiento, del que desconocemos todas sus características, proporcionó 1 punta Palmela que carece igualmente de información contextual al proceder de una colección particular.
- Necrópolis de Las Aguilillas (Ardales-Campillos): la necrópolis de cuevas artificiales de Las Aguilillas-Parque Ardales ha proporcionado 2 puntas Palmela y 2 punzones asociados a enterramientos datados por sus excavadores en el II milenio (Ramos et al., 1997), aunque a nuestro entender pueden corresponder más bien al tránsito del III al II milenio cal AC.

- Cerro García (Casabermeja): asentamiento situado en la vertiente septentrional de los Montes de Málaga, con buena posición estratégica y control de la vía de tránsito natural que constituye la depresión de Colmenar-Periana, así como de otros yacimientos que se mencionan aquí. No ha sido excavado, pero su material de superficie aportó 1 punta Palmela (Marqués, 1985), 1 fragmento de malaquita y 1 pequeño puñal de remaches que puede estar en relación con una perduración del yacimiento hasta el iI milenio cal AC (Rodríguez-Vinceiro et al., 1992).

Para la Edad del Bronce contamos con una amplia nómina de yacimientos que han aportado objetos metálicos, si bien en muchos casos se trata de hallazgos aislados con muy poca o nula información contextual. Por este motivo relacionaremos solo los más importantes para nuestro propósito, remitiéndonos para el resto a publicaciones anteriores (Rodríguez-Vinceiro et al., 1992).

- Necrópolis de Alcaide (Antequera): si bien la mayoría de los sepulcros excavados en la roca que la componen debieron de ser realizados durante la Edad del Cobre, su dilatado uso convierte a esta necrópolis en una de las más importantes de la provincia durante el iI milenio cal ANE. Los objetos metálicos recuperados en ella, sin ser abundantes, tienen a menudo una especial significación. Los sepulcros que los han proporcionado son los siguientes:

- Sepulcro n. ${ }^{\circ}$ 14: tanto el material cerámico como las fechas C14 que poseemos sitúan su etapa de uso en un Bronce Tardío - CNA2276, $2945 \pm 40$ вр, 1263-1023 cal AC $2 \sigma$; CNA-2273, $3045 \pm 40$ BP, $1414-1135$ cal AC 


\begin{tabular}{|c|c|c|c|c|c|c|c|}
\hline Овјето & INVENTARIO & YACIMIENTO & $206 \mathrm{~Pb} / 204 \mathrm{~Pb}$ & $207 \mathrm{~Pb} / 204 \mathrm{~Pb}$ & $208 \mathrm{~Pb} / 204 \mathrm{~Pb}$ & $207 \mathrm{~Pb} / 206 \mathrm{~Pb}$ & $208 \mathrm{~Pb} / 206 \mathrm{~Pb}$ \\
\hline Escoria & EC-113 & El Castillejo & 22,209 & 15,880 & 39,008 & 0,71503 & 1,75640 \\
\hline Crisol & EC-118 & El Castillejo & 18,604 & 15,656 & 38,659 & 0,84154 & 2,07798 \\
\hline Resto fundición (metal) & EC-105 & El Castillejo & 21,083 & 15,819 & 39,025 & 0,75032 & 1,85101 \\
\hline Resto fundición (metal) & EC-108 & El Castillejo & 19,970 & 15,793 & 38,909 & 0,79086 & 1,94839 \\
\hline Resto fundición (metal) & EC-112 & El Castillejo & 19,302 & 15,722 & 38,640 & 0,81454 & 2,00188 \\
\hline Hacha plana & EC-6 & El Castillejo & 18,305 & 15,621 & 38,251 & 0,85334 & 2,08961 \\
\hline Hacha plana & EC-7 & El Castillejo & 18,224 & 15,611 & 38,171 & 0,85660 & 2,09455 \\
\hline Punzón (frag.) & EC-109 & El Castillejo & 18,511 & 15,657 & 38,629 & 0,84583 & 2,08684 \\
\hline Punzón (frag.) & EC-110 & El Castillejo & 18,816 & 15,656 & 38,706 & 0,83203 & 2,05711 \\
\hline Sierra (frag.) & EC-111 & El Castillejo & 18,484 & 15,635 & 38,416 & 0,84588 & 2,07834 \\
\hline Lámina (frag.) & EC-107 & El Castillejo & 18,200 & 15,618 & 38,166 & 0,85816 & 2,09703 \\
\hline Escoria & PH-3 & Peña de Hierro & 18,571 & 15,662 & 38,812 & 0,84340 & 2,08998 \\
\hline Punta palmela & $\mathrm{CP}-2$ & Los Peñones & 18,454 & 15,637 & 38,525 & 0,84740 & 2,08771 \\
\hline Resto fundición (metal) & ALC-6 & Alcaide & 18,701 & 15,631 & 38,741 & 0,83581 & 2,07156 \\
\hline Escoplo & ALC- 20 & Alcaide & 18,200 & 15,620 & 38,243 & 0,85825 & 2,10131 \\
\hline Puñal lengüeta & ALC-16 & Alcaide & 18,471 & 15,620 & 38,294 & 0,84570 & 2,07321 \\
\hline Punta palmela & PO-3 & \begin{tabular}{|l|} 
Peñón del Oso \\
\end{tabular} & 18,222 & 15,666 & 38,362 & 0,85970 & 2,10519 \\
\hline Hacha plana & Ст-1 & Cortijo del Tardón & 18,299 & 15,643 & 38,320 & 0,85485 & 2,09407 \\
\hline Puñal lengüeta & Ст-2 & Cortijo del Tardón & 18,172 & 15,609 & 38,160 & 0,85896 & 2,09992 \\
\hline Punta palmela & СТ-5 & Cortijo del Tardón & 18,291 & 15,624 & 38,335 & 0,85418 & 2,09587 \\
\hline Escoplo & мСH-2 & Marimacho & 18,346 & 15,619 & 38,249 & 0,85136 & 2,08489 \\
\hline Punzón & МCH-1 & Marimacho & 20,348 & 15,774 & 39,059 & 0,77519 & 1,91955 \\
\hline
\end{tabular}

FIG. 8. Análisis de isótopos de plomo de restos arqueológicos procedentes de yacimientos de Tierra de Antequera.

2 б; CNA-2274, $3115 \pm 40$ вP, 1494-1269 cal AC $2 \sigma$; GrN-16061, $3180 \pm 100$ BP, 1691-1135 cal AC 2 o; CNA-2275, $3475 \pm 40$ BP, 18951690 cal AC 2 o-. En metal proporcionó un solo fragmento que corresponde a una posible hoz, cuyo análisis de composición elemental reveló que estaba realizado en bronce binario, con un porcentaje de Sn superior al 8\%, habitual en la Península Ibérica en el último tercio del II milenio. En un ámbito más local esta pieza constituye el primer objeto de bronce recuperado en un contexto seguro y fechado mediante C14 de la provincia (Marqués y Aguado, 2012; Tovar et al., 2014).

- Sepulcro n.o 9: el expolio sufrido por este sepulcro ha sido el causante de que el ajuar recuperado sea muy escaso. No obstante, su excavación deparó un conjunto de piezas metálicas interesante: una diadema y varias espirales realizadas en plata nativa, además de un fragmento laminar que puede haber correspondido a una punta foliácea, un punzón y otro fragmento laminar fracturado en ambos extremos, realizados todos en cobre arsenicado $-3 \%$ As, aproximadamente-. Para el conjunto se propone una clasificación cultural de Bronce Pleno o Tardío, y un marco cronológico similar al del sepulcro n. ${ }^{\circ} 15$, que sí contaba con dataciones absolutas -GrN-16064,

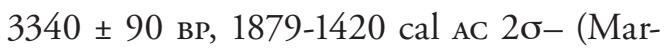
qués y Aguado, 2012).

- Sepulcro n. ${ }^{\circ}$ 12: es uno de los excavados a mediados del s. xx por Giménez Reyna, quien lo encontró intacto. El material recuperado en él corresponde claramente a dos cronologías distintas pues, mientras que la mayoría de los objetos se pueden asignar tipológicamente al Calcolítico - platos/fuentes de borde engrosado y puntas de flecha-, los dos puñales de cobre recuperados, uno de remaches y otro de escotaduras, son elementos típicos de la Edad del Bronce, aunque no permiten precisar más su cronología (Marqués y Aguado, 2012). 
- Material de superficie: además de los relacionados, la necrópolis ha proporcionado materiales arqueológicos descontextualizados procedentes de los saqueos y remociones de que ha sido objeto el yacimiento. Entre estos, cabe destacar, para los fines que ahora nos interesan, un puñal de remaches de cobre arsenicado $-1,5 \%$ As-.

- Peña de los Enamorados (Antequera): gran yacimiento de la Vega de Antequera, que se extiende sobre todo por las laderas o y s de este hito geográfico. No ha sido excavado, aunque por su material de superficie podemos bosquejar una secuencia que se inicia en el Neolítico y alcanza hasta época romana. Frecuente objeto de saqueos y expolios, ha proporcionado diversos fragmentos de objetos metálicos y 11 gotas de cobre que por su composición elemental - $\mathrm{Cu}$ y As exclusivamente- podrían estar relacionados con una eventual actividad metalúrgica desarrollada durante el III y II milenio, junto a varios puñales de remaches que nos remiten más concretamente a la Edad del Bronce. En colección privada obra también un crisol con peana $\mathrm{y}$ visibles restos de actividad metalúrgica que no han podido ser analizados (Rodríguez-Vinceiro y Fernández-Rodríguez, 1998).

- Cortijo de El Tardón (Antequera):

- Sepulcro A: aunque similar en su factura al sepulcro B, El ajuar de este se componía de adornos realizados en cobre (espirales) junto a punzones, un escoplo y algunas plaquitas de posible función ornamental. El saqueo a que fue sometido causó su vaciado casi completo, por lo que la información contextual recuperada es escasa (Fernández-Ruiz et al., 1997). Contamos, no obstante, con una fecha absoluta -UGRA-260, $3530 \pm 70$ вP, 2106-1686 cal AC 2o-que sitúa su momento de uso en la primera mitad del II milenio.

- Cortijo de Gonzalo (Colmenar): pequeña necrópolis compuesta por cuatro o cinco cistas que se encuentran en la actualidad destruidas. Su excavación en 1973 permitió recuperar 2 escoplos y
1 puñal de remaches (Ferrer, 1974; Baldomero y Ferrer, 1984).

- Cerro de la Horca (Teba): asentamiento no excavado, pero sometido a un intenso expolio, en el que abundan las piezas de metal de tipología del Bronce, muchas de ellas en estado fragmentario. En el Museo Histórico Municipal de Teba se conservan 34 de ellas, siendo en su mayor parte puntas -tipo Palmela y de pedúnculo y aletas-, puñales de remaches y hachas planas.

- Necrópolis de Rodahuevos (Antequera-Campillos): actualmente cubierta por las aguas del pantano del Conde de Guadalhorce. Se localizaron siete estructuras funerarias, de las cuales se excavaron en 1995 por el procedimiento de urgencia cinco. Proporcionó 2 espirales de plata y 1 de cobre (Fernández-Rodríguez et al., 1999).

\section{Análisis de isótopos de plomo}

Las muestras arqueológicas y geológicas se analizaron con un espectrómetro de masas con fuente de ionización térmica-Tims- en el Servicio de Geocronología y Geoquímica -sGrker- de la UPV.

En primer lugar, se han comparado entre sí todos los materiales procedentes de El Castillejo (Fig. 9) con intención de verificar la hipótesis ya formulada de la existencia de una producción local, distribuyéndolos en tres categorías: mineral recuperado en el yacimiento, restos de producción y objetos acabados.

De esta primera comparación se han obtenido tres conclusiones: que este asentamiento explotó, al menos, dos fuentes de recursos, una de ellas muy radiogénica; que los datos confirman la existencia de producción in situ de algunos de los objetos analizados, y, por último, que una parte de las muestras obtenidas de los objetos manufacturados se aleja significativamente de los valores arrojados por los minerales y restos de producción, lo que sugiere una posible actividad de intercambio.

En segundo lugar se han comparado entre sí los análisis procedentes de los yacimientos arqueológicos de las Tierras de Antequera (Fig. 10), distribuyéndolos en las siguientes categorías: minerales 


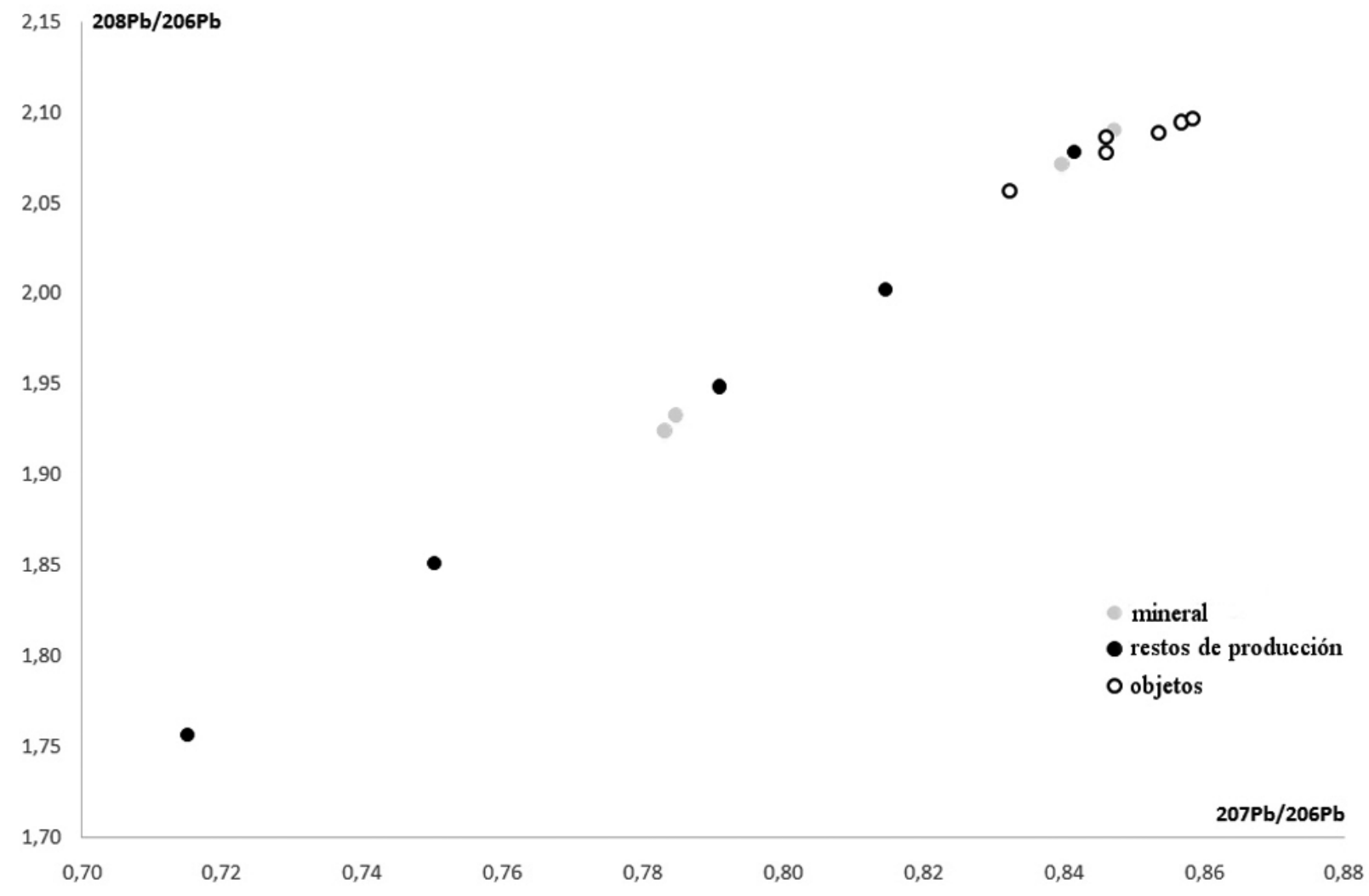

FIG. 9. Representación de las ratios isotópicas de los materiales de El Castillejo (Almogía, Málaga).

-Castillejo, Cerro García, Peńones-, restos de producción -Castillejo, Alcaide- y objetos -Castillejo, Alcaide, Comandante, Peñones, Tardón, Marimacho y Peñón del Oso-, con objeto de establecer correspondencias entre los distintos tipos de restos que sugieran el desarrollo en alguno de estos asentamientos de toda la cadena operativa del proceso productivo, con independencia del origen de la materia prima empleada.

Para analizar la posible producción local de cobre por parte de los asentamientos de las Tierras de Antequera y determinar el posible origen del mineral, se han correlacionado las muestras arqueológicas con los datos disponibles de minerales de los afloramientos maláguides, dando como resultado la existencia de una coincidencia básica de una serie de objetos y minerales de yacimientos malagueños -Castillejo, Silillo, Peñones y Alcaide- con una muestra mineral de la mina de Casacara. Aunque el campo isotópico de esta mina no está definido pues contamos con una sola muestra analizada, la similitud isotópica de estas muestras en todos los ejes, así como su cercanía geográfica, hacen que la explotación de esta mina por parte de las comunidades malagueńas pueda plantearse como una hipótesis factible. El máximo nivel de coincidencia se da entre una punta de tipo Palmela de los Peñones y una muestra mineral de Cerro García, lo cual podría indicar, bien un intercambio de objetos acabados entre ambos yacimientos, bien que los dos están explotando los mismos recursos cupríferos -ambos yacimientos están muy próximos entre sí y ambos, a la vez, de las minas de Casacara-. Como ya se ha mencionado, el campo isotópico de Casacara no está definido, pero, sobre la base de estos datos provisionales, proponemos la existencia en Casacara de un punto de extracción de recursos minerales explotado, quizá simultáneamente, por Peñones, Cerro García y Castillejo, en la última mitad del III milenio alcanzando hasta el tránsito del III al II milenio 


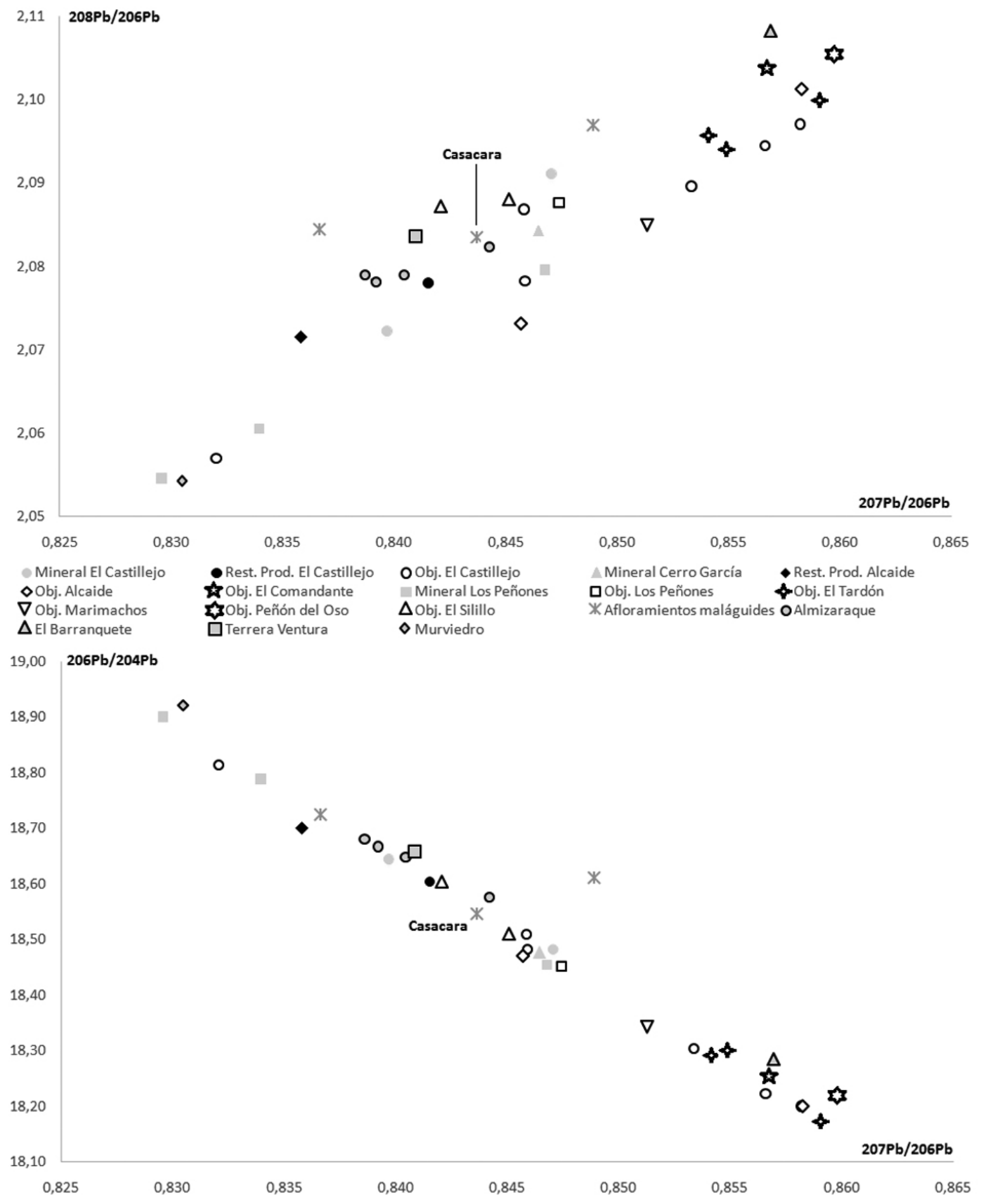

FIG. 10. Representación de las ratios isotópicas de los materiales de Tierras de Antequera en relación a los del SE. Las muestras minerales (tanto arqueológicas como de los afloramientos maláguides) se representan en gris, los restos de producción en negro y los objetos acabados en blanco con borde negro en el caso de los yacimientos malagueñoso gris con borde negro en el caso de otros yacimientos no malagueños. 
110 F. Rodríguez, M. Murillo, L.-E. Fernández e I. Montero / Metalurgia prehistórica en Tierras de Antequera...

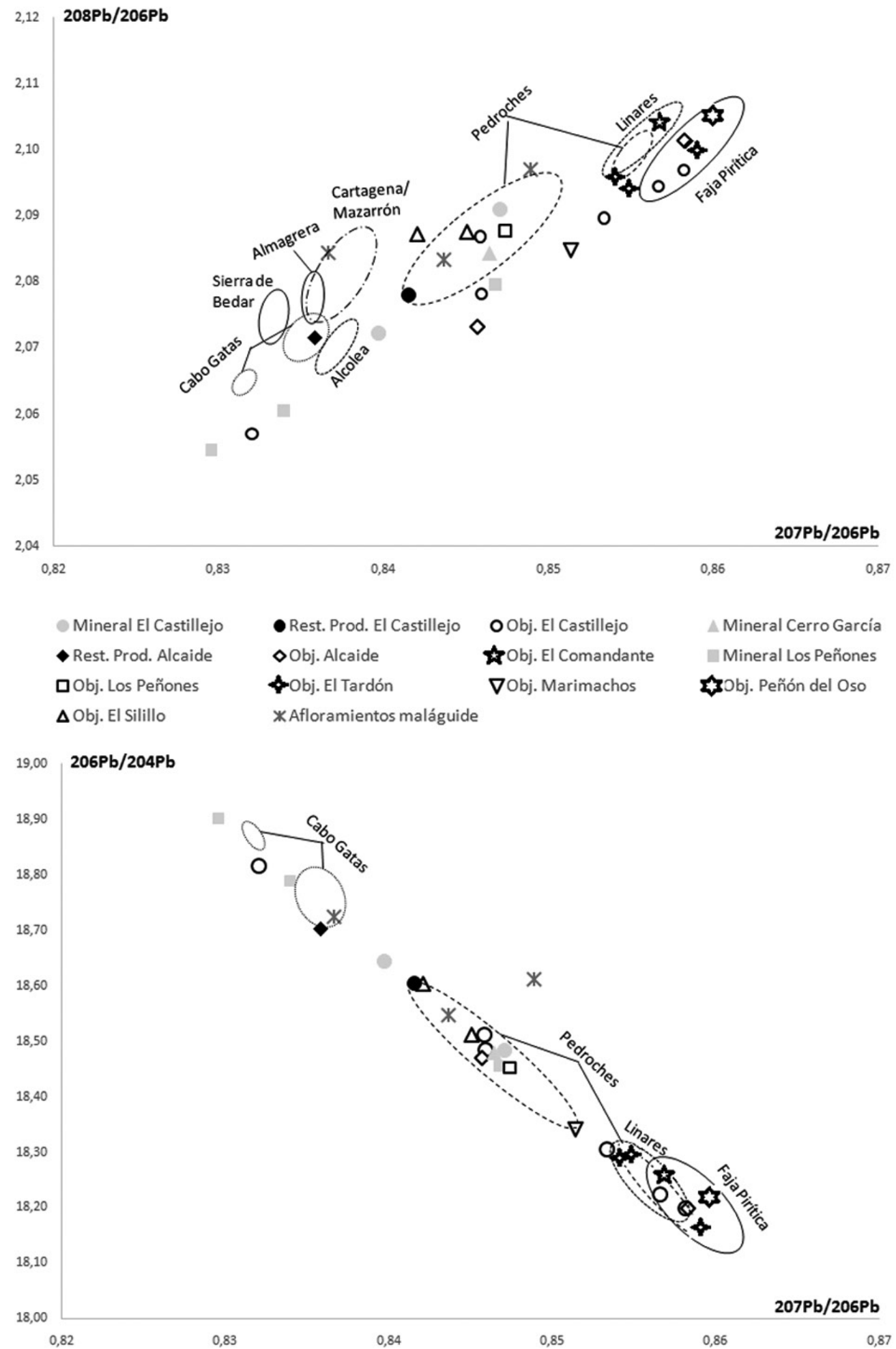

Fig. 11. Representación de las ratios de isótopos de plomo de los materiales de Tierras de Antequera en relación a las de las principales mineralizaciones del s peninsular. 
AC, ya que los registros de los dos primeros, aun no disponiendo de dataciones C14, podrían definirse culturalmente como Cobre Tardío-Final con una fuerte presencia campaniforme. Además, un punzón de Castillejo coincide con una muestra mineral de Los Peñones y, en el otro extremo de la gráfica, la sierra de Castillejo también coincide con otra muestra mineral de Peñones, sugiriendo, dada la proximidad geográfica de ambos yacimientos, la existencia de intercambios a corta distancia o de recursos compartidos.

Siguiendo con la línea argumental del trabajo, se ha investigado la posible existencia, por parte de los asentamientos calcolíticos de las Tierras de Antequera, de recursos minerales compartidos con el SE (Fig. 10), dando como resultado una similitud isotópica entre restos minerales de Málaga, restos de producción de Almizaraque y Terrera Ventura, un crisol de Castillejo y una pieza de El Silillo que puede sugerir la existencia de un cierto nivel, aunque moderado, de explotación compartida de recursos con el SE.

La misma comparación se ha realizado con el otro foco metalúrgico andaluz, el so (Fig. 11), observando la existencia de un numeroso grupo de muestras, constituido exclusivamente por objetos acabados, que se sitúa a considerable distancia de los minerales y los restos de producción de Málaga y, sin embargo, coincide en todos los ejes con el campo isotópico de la Faja Pirítica -se han utilizado los datos publicados por Marcoux, 1998; Stos-Gale et al., 1995-. La coincidencia es clara en el caso de seis objetos procedentes de Peñón del Oso, Tardón, Alcaide y Castillejo. Estos datos se interpretan como producto de intercambio con el so, que demostraría la existencia de una interrelación entre las comunidades del so y de las Tierras de Antequera durante el III milenio. Estos contactos estarían favorecidos por la fácil vía de penetración que, remontando el Guadalquivir, alcanza la depresión de Antequera por el no.

\section{Conclusiones}

A pesar de que aún no se han identificado inequívocamente explotaciones mineras prehistóricas en el ámbito de las Tierras de Antequera, la aplicación de la técnica de los isótopos de plomo a diferentes muestras extraídas de una gran variedad de elementos relacionados con la metalurgia procedentes de la zona permite considerar atestiguada la existencia de una producción metalúrgica local en el ámbito de Málaga durante parte, al menos, de la Prehistoria Reciente. Esta actividad productiva se concreta en los yacimientos que rodean la comarca de Los Montes, que constituye una zona minera con personalidad propia cuya explotación se inicia, a tenor de los resultados obtenidos, hacia mediados del III milenio cal AC y se prolonga, al menos, hasta los primeros siglos del in milenio, a pesar de estar situada entre los dos principales focos metalúrgicos de la Península Ibérica durante la prehistoria.

Para este periodo, la zona en que este proceso se materializa de una forma más evidente es la formada por el encuentro entre el reborde septentrional de la comarca de Los Montes, el Campo de Cámara y el río Guadalmedina. Allí, como ya se ha dicho, conviven en pocos kilómetros cuadrados tres asentamientos con un estratégico control visual del entorno -Los Peñones, Cerro García y El Castillejo-, una estación de arte rupestre -Peñas de Cabrera-, cinco áreas de necrópolis -Tajillo del Moro, Casa Arias, Casabermeja, Roza del Caracol y Cortijo de Gonzalo-, un punto de aprovisionamiento de sílex y dos mineralizaciones de cobre de fácil beneficio - Casacara y Peñas de Cabrera-. Tal concentración de yacimientos arqueológicos y recursos minerales dio pie a formular hace años una hipótesis (Rodríguez-Vinceiro y Fernández-Rodríguez, 1998) sobre la posible explotación de la zona minera de Casacara por los tres asentamientos citados. Los análisis de isótopos de plomo comentados en el apartado anterior le otorgan verosimilitud a esta hipótesis, si bien un adecuado contraste requeriría definir con precisión el campo isotópico de las minas de Casacara mediante la ampliación del número de muestras analizadas.

El asentamiento de El Castillejo se configura, en el estado actual de la investigación, como el centro metalúrgico más destacado de la zona, siendo el más extenso y estratégicamente mejor situado de los 
tres desde el punto de vista defensivo, desarrollando una producción metalúrgica no destinada exclusivamente al autoabastecimiento, sino también al intercambio regional. Quizá sea en este contexto en el que hay que entender la presencia en la estratigrafía de El Castillejo de productos como la cerámica campaniforme -en escasa cantidad-y abundantes restos de malacofauna pertenecientes mayoritariamente a la especie Donacilla cornea (Rodríguez Vinceiro y Fernández Rodríguez, 1998) en contextos de consumo que pueden estar indicando una circulación exterior de la producción metalúrgica hacia la costa (Nocete et al., 2004). Junto a este, otros dos asentamientos de menor extensión, los ya citados de Los Peńones y Cerro García, pueden ser también considerados, a tenor de los vestigios recuperados en ellos y las analíticas realizadas, como centros productores. No tenemos datos suficientes para precisar el carácter de este uso compartido de las minas de Casacara ya que, a la mencionada escasez de análisis, hay que añadir la falta de excavaciones sistemáticas en la zona, que solo cuenta con el sondeo realizado en El Castillejo y la excavación del sepulcro de Tajillo del Moro. Hacia finales del III milenio el gran asentamiento de El Castillejo ha sido ya abandonado, mientras que Los Peñones y Cerro García parecen prolongar su periodo de uso, según el material de superficie recuperado, hasta principios del II milenio cal ANE, aunque sin alcanzar una fase de Bronce Pleno.

De manera simultánea, los yacimientos situados a mayor distancia de los recursos mineros, como Marimacho o El Silillo, en plena vega de Antequera, y Peñón del Oso, en la dorsal bética, practican, a tenor de los vestigios recuperados en ellos, una metalurgia de transformación del metal en objetos acabados, ya que en ellos están ausentes los restos minerales, tanto sin procesar como parcialmente reducidos. No obstante, aunque la producción metalúrgica en los asentamientos malagueños ha quedado atestiguada, la presencia de metal foráneo, especialmente del so, es significativa.

Para el II milenio cal AC, como ya se ha mencionado, nuestro conocimiento es mucho más incompleto, pues no tenemos todavía datos de isótopos de plomo de objetos adscritos al Bronce Pleno, por lo que nos faltan elementos de juicio para entender la metalurgia local de esta última fase. No obstante los datos disponibles nos inducen a pensar que al concentrarse la población en asentamientos más extensos, de más fácil defensa y de mayor control visual del entorno, la explotación de los recursos metalíferos se dirige hacia lugares situados en la proximidad inmediata de los poblados -como en el caso del Cerro de la Peluca (Marqués y Aguado, 2012), en la cuenca del río Campanillas-, abandonándose las antiguas minas. Por otra parte, en la vega de Antequera, donde estos recursos, como ya hemos visto, están ausentes, se seguiría practicando una metalurgia de fundición o refundición de piezas amortizadas.

\section{Bibliografía}

Aguayo, P. y García Sanjuán, L. (2006): "The megalithic phenomenon in Andalusia (Spain): An overview". En Joussaume, R.; Laporte, L. y Scarre, C. (eds.): Origin and development of the megalithic monuments of Western Europe. Proceedings Internat. Symposium (Bougon, 2002). Niort: Conseil Général de Deux Sèvres, pp. 451-476.

Aguayo, P.; Lobato, R. y Carrilero, M. (1987): “Excavaciones arqueológicas en el casco antiguo de Ronda (Málaga). Agosto 1984". En Anuario Arqueológico de Andalucía, 1985. Sevilla, vol. III, pp. 236-239.

Arboledas, L.; Contreras, F.; Moreno, A.; Dueñas, J. y Pérez Sánchez, A. A. (2006): "La mina de José Martín Palacios (Baños de la Encina, Jaén). Una aproximación a la minería antigua en la cuenca del Rumblar", Arqueología y Territorio, 3, pp. 179-195.

Arribas, A.; Molina, F.; De la Torre, F.; Nájera, T. y SÁez, L. (1978): "El poblado de la Edad del Cobre de 'El Malagón' (Cúllar-Baza, Granada)", Cuadernos de Prehistoria de la Univ. de Granada, 3, pp. 67-116.

Arribas Jr., A. y Tosdal, R. (1994): "Isotopic composition of $\mathrm{Pb}$ in ore deposits of the Betic Cordillera, Spain: Origin and relationship to other European deposits", Economic Geology, 89, pp. 1074-1093.

Baldomero, A. y Ferrer, J. (1984): "Las necrópolis en cistas de la provincia de Málaga”, Cuadernos de Prehistoria de la Univ. de Granada, 9, pp. 175-193. 
Baldomero, A.; Ferrer, J. y Marqués, I. (1988): “Excavaciones de la Univ. de Málaga durante 1987, en yacimientos de Prehistoria Reciente", Baetica, 11, pp. 153-162.

BARCELÓ, J. A. (1997): “¿Podemos definir arqueológicamente las formas de interacción social?”. En MarTín Ruiz, J. M.; Martín Ruiz, J. A. y Sánchez BanDera, P. J. (eds.): Arqueología a la Carta. Relaciones entre Teoría y Método en la Práctica Arqueológica. Málaga: Diput. de Málaga, pp. 61-79.

Berdichewsky, B. (1964): Los enterramientos en cuevas artificiales del Bronce I Hispánico. Biblioteca Praehistorica Hispanica, vi. Madrid: Csic.

Budd, P.; Haggerty, R.; Pollard, A.; Scaife, B. y Thomas, R. (1996): "Rethinking the quest for provenance", Antiquity, 70, pp. 168-174.

Dayton, J. E. y Dayton, A. (1986): "Uses and limitations of lead isotopes in archaeology". En Olin, J. S. y Blackman, M. J. (eds.): Proceedings 24th Intern. Archaeometry Symposium. Washington: Smithsonian Institution Press, pp. 13-41.

Fernández Rodríguez, L. E.; Rodríguez Vinceiro, F. J.; Clavero, J. L.; Romero, J. C.; Von Thode, C.; García, A.; Barrera, M. y Huertas, C. (1992): "Informe preliminar. Proyecto: Prospección arqueometalúrgica de la provincia de Málaga. Campaña de 1990. Sector suroccidental del Maláguide". En Anuario Arqueológico de Andalucia/1990. Sevilla, vol. II, pp. 131-137.

Fernández Rodríguez, L. E.; Rodríguez Vinceiro, F. J.; Palomo, A.; Santamaría, J. A.; Suárez Padilla, J.; Navarro, I.; Arancibia, A.; Escalante, M. y Ángel, J. M. (1999): "Informe preliminar de la excavación arqueológica de urgencia en la necrópolis del Bronce del Cortijo de Rodahuevos (Antequera-Campillos, Málaga)". En Anuario Arqueológico de Andalucia/1995. Sevilla, vol. III, pp. 384-390.

Fernández Rodríguez, L. E.; Tomassetti, J. M.; RiQuelme, J. A.; Salado, J. B.; Rodríguez Vinceiro, F. J. y Compaña, J. M. (2014a): "El Silillo, un asentamiento calcolítico en la depresión de Antequera", Menga, 5, pp. 101-121.

Fernández Rodríguez, L. E.; Cisneros, M. a I.; Palomo, A.; López Tito, B.; Ruiz Somavilla, I.; Crespo, M.; Ferrando, M. y Espinar, A. (2014b): "Nuevos aspectos sobre el rito de enterramiento colectivo en la comarca de Antequera. El hipogeo del Cerro del Comandante". En García Alfonso, E. (ed.): II Congreso de Prehistoria de Andalucía (Antequera, 2012). Sevilla: Junta de Andalucía, pp. 185-189.
Fernández Ruiz, J.; Marqués, I.; Ferrer, J. y BalDOMERo, A. (1997): "Los enterramientos colectivos de El Tardón (Antequera, Málaga)". En Balbín, R. y Bueno, P. (coords.): II Congreso de Arqueología Peninsular (Zamora, 1996). Zamora: Fund. Rei Afonso Henriques, t. II, pp. 371-380.

Ferrer, J. (1974): "Hallazgo de unas cistas megalíticas en el término de Colmenar", Jábega, 7, pp. 71-75.

Ferrer, J.; Baldomero, A. y Garrido, A. (1987): "El cerro de Marimacho (Antequera, Málaga)", Baetica, 10, pp. 179-188.

Ferrer, J.; Marqués, I.; Fernández Ruiz, J.; Baldomero, A. y Garrido, A. (1980): "El sepulcro megalítico del 'Tajillo del Moro' (Casabermeja, Málaga)”, Cuadernos de Prehistoria y Arqueología de la Univ. de Granada, 5, pp. 81-118.

Gale, N. H. y Stos-Gale, Z. (1996): "Lead isotope methodology: the possible fractionation of lead isotope compositions during metallurgical processes", Archaeometry, 94, pp. 287-299.

García González, D.; Morgado, A.; Martínez Sevilla, F.; Martínez Sánchez, R. M.; Fernández Martín, S.; Gutiérrez Rodríguez, M. y SÁnchez Bandera, P. (2014): "Intervención en el Cerro de Marimacho (Antequera, Málaga): primeras evidencias de la existencia de un foso", Menga, 5, pp. 247-257.

García Sanjuán, L. y Odriozola, C. (2012): "La cronología radiocarbónica de la Edad del Bronce $(c$. 2200-850 cal ANe) en el suroeste de la Península Ibérica”. En Jiménez Ávila, J.: Sidereum Ana II: el río Guadiana en el Bronce Final. Anejos de Archivo Español de Arqueología, LXII. Madrid: CsIC, pp. 363-387.

Graeser, S. y Friedrich, G. (1970): "Zur Frage der Altestellung und Genese der Blei-Zink vorkommen der Sierra de Cartagena in Spanien", Mineralium Deposita, 5 (4), pp. 365-374.

Hunt, M. (1998): "Análisis de isótopos de plomo aplicados a la arqueología". En Fernández, J. y Sarabia, F. J. (eds.): Arqueometalurgia del Bronce. Introducción a la metodología de trabajo. Studia Archaeologica, 8. Valladolid: Univ. de Valladolid, pp. 45-68.

Hunt, M. (2003): Prehistoric Mining and Metallurgy in South West Iberian Peninsula. BAR Intern. Ser., 1188. Oxford: Archaeopress.

Hunt, M.; Contreras, F. y Arboledas, L. (2011): "La procedencia de los recursos minerales en el poblado de la Edad del Bronce de Peńalosa (Baños de la Encina, Jaén): resultados de análisis de isótopos de plomo". En Mata, J. M; Torrí, L.; Fuentes, M. N.; Neira, A. y Puche, O. (eds.): v Simposio Intern. sobre minería y metalurgia históricas en el Suroeste 
europeo. Homenaje a C. Domergue. (León, 2008). La Pobla de Segur: Univ. de León, pp. 195-206.

IXER, R. (1999): "The role of ore geology and ores in the archaeological provenancing of metals". En YounG, S. M.; Pollard, A. M.; Budd, P. e Ixer, R. A. (eds.): Metals in Antiquity. Oxford: Archaeopress, pp. 43-52.

Klein, S.; Domergue, C.; Lahaye, Y.; Brey, G. P. y Von Kaenel, H.-M. (2009): "The lead and copper isotopic composition of copper ores from the Sierra Morena (Spain)", Journal of Iberian Geology, 35 (1), pp. 59-68.

Leisner, V. (1965): Die Megalithgräber der Iberischen Halbinsel. Der Western. Berlin: De Gruyter.

Leiva, J. A. y Ruiz GonzÁlez, B. (1977): "Materiales arqueológicos del Cerro de Antequera", Jábega, 19, pp. 15-18.

Marcoux, E. (1997): "Lead Isotope Systematics of the Giant Massive Sulphide Deposits in the Iberian Pyrite Belt”, Mineralium Deposita, 33, pp. 45-58.

Marqués, I. (1984): "El poblado del Llano de la Virgen (Coín, Málaga). Avance de las campañas de excavaciones realizadas hasta 1983", Baetica, 7, pp. 147-158.

Marqués, I. (1985): "Materiales de la Edad del Cobre procedentes del Cerro García (Casabermeja, Málaga)", Baetica, 8, pp. 149-164.

MARqués, I. (1990): "El yacimiento de Alcaide (Antequera, Málaga). Campaña de excavaciones de 1987". En Anuario Arqueológico de Andalucía/1990. Sevilla, vol. II, pp. 268-270.

MARQués, I. y Aguado, T. (2012): Los enterramientos de la Edad del Bronce en la provincia de Málaga. Málaga: Univ. de Málaga.

Marqués, I.; Aguado, T.; Baldomero, A. y Ferrer, J. (2004): "Proyectos sobre la Edad del Cobre en Antequera (Málaga)". En III Simposio de Prehistoria Cueva de Nerja. Homenaje a Antonio Arribas Palau (Nerja, 2000). Málaga: Fund. Cueva de Nerja, pp. 238-260.

MÉRIDA, M. (1997): "La cobertera maláguide y su significado paisajístico", Baetica, 19-1, pp. 185-196.

Montero, I. y Hunt, M. (2006): "Aplicació d'anàlisis d'isotops en la investigació arqueometallúrgica”, Cota Zero, 21, pp. 87-95.

Montero, I. y Murillo, M. (2010): "La producción metalúrgica en las sociedades argáricas y sus implicaciones sociales: una propuesta de investigación", Menga, 1, pp. 37-51.

Morales, A.; Márquez, J. E. y Recio, A. (1986): “El poblado calcolítico del Peńón del Oso, Villanueva del Rosario (Málaga)", Mainake, IV-v, pp. 13-38.
Moreno, A. (1987): "Excavación arqueológica de urgencia en el Peñón del Oso (Villanueva del Rosario, Málaga), 1985”. En Anuario Arqueológico de Andalucía 1985. Actividades de Urgencia. Sevilla, pp. 244-250.

Morgado, A.; Martínez Sevilla, F.; Garzón, J.; Jiménez Cobos, F.; Berdejo, A.; Bermúdez, R.; Ruiz Ruano, F.; Gutiérrez Rodríguez, M.; Fernández Martín, S.; Ortiz González, J. y Lozano, J. A. (2013): "Villavieja (Algarinejo, Granada) un recinto amurallado de la Edad del Cobre en el Poniente Granadino. Avance de la campaña de 2012", Antiquitas, 25, pp. 39-48.

Murillo, M.; Martinón, M.; Camalich, M. D.; Martín, D. y Molina, F. (2017): "Early metallurgy in SE Iberia. The workshop of Las Pilas (Mojácar, Almería, Spain)", Archaeological and Anthropological Sciences, 9 (7), pp. 1539-1569.

Nocete, F.; Lizcano, R. y Nieto, J. M. (2004): “Aproximación a las prácticas sociales: contextos y tiempo en Cabezo Juré". En Nocete, F. (coord.): Odiel. Proyecto de investigación arqueológica para el análisis de la desigualdad social en el suroeste de la peninsula Ibérica. Sevilla: Junta de Andalucía, pp. 343-375.

Nocete, F.; Queipo, G.; Sáez, R.; Nieto, J. M.; InÁcio, N.; Bayona, M. R.; Peramo, A.; Vargas, J. M.; Gil Ibarguchi, J. I. y Santos, J. F. (2008): "The smelting quarter of Valencina de la Concepción (Seville, Spain): the specialised copper industry in a political centre of the Guadalquivir Valley during the Third millennium вс (2750-2500 вС)", Journal of Archaeological Science, 35, pp. 717-732.

Oxalid. Oxford Archaeological Lead Isotope Database. http://oxalid.arch.ox.ac.uk/.

Perdiguero, M. (1989-90): "Excavaciones arqueológicas efectuadas en Cauche el Viejo (Antequera, Málaga)", Mainake, XI-XII, pp. 57-80.

Perdiguero, M. (1995): Aratispi: Cauche el viejo, Antequera: Investigaciones arqueológicas. Málaga: CEDMA.

Pernicka, E. (2014): "Provenance determination of archaeological metal objects". En Roberts, B. W. y Thornton, C. P. (eds.): Archaeometallurgy in Global Perspective. New York: Springer, pp. 239-268.

Ramos, J.; Espejo, M. M.; Recio, A.; Cantalejo, P.; Martín, E.; Durán, J. J.; Castañeda, V.; Pérez Rodríguez, M. y Cáceres, I. (1997): "La necrópolis colectiva del Cerro de Las Aguilillas (Ardales-Campillos, Málaga). Inferencias socioeconómicas", Revista Atlántica-Mediterránea de Prehistoria y Arqueología Social, 1, pp. 159-180. 
Rehder, J. E. (1994): "Blowpipes versus Bellows in Ancient Metallurgy", Journal of Field Archaeology, 21, pp. $245-250$.

Rodríguez Vinceiro, F. J. (2003): "Caracterización de la metalurgia prehistórica de origen maláguide: planteamientos iniciales", Mainake, xxv, pp. 293-308.

Rodríguez Vinceiro, F. J. y Fernández Rodríguez, L. E. (1998): "La explotación de recursos minerometalúrgicos cupríferos durante la Prehistoria Reciente en el Bético de Málaga”. En Bernabeu, J.; Orozco, T. y Terradas, X. (eds.): Los recursos abióticos en la Prehistoria. Caracterización, aprovisionamiento e intercambio. Valencia: Univ. de Valencia, pp. 155-172.

Rodríguez Vinceiro, F. J.; Fernández Rodríguez, L. E.; Clavero, J. L.; Romero, J. C.; Von Thode, C.; García Pérez, A.; Huertas, C. y BarreRA, M. (1991): "Prospección arqueometalúrgica de la provincia de Málaga: campańa de 1989. El sector nor-occidental del Maláguide". En Anuario Arqueológico de Andalucía 1989. Sevilla, vol. II, pp. 75-80.

Rodríguez Vinceiro, F. J.; Fernández Rodríguez, L. E.; Clavero, J. L.; Romero, J. C.; Von Thode, C.; García, A.; Suárez, J.; Barrera, M. y Paloмо, A. (1992): "Estado actual de la investigación arqueometalúrgica prehistórica en la provincia de Málaga”, Trabajos de Prehistoria, 49, pp. 217-242.

Romero, J. C. (2003): Minerales y rocas de la provincia de Málaga. Málaga: Cedma.

Santos, J. F.; García de Madinabeitia, S.; Gil, J. I. y Palero, F. (2004): "A lead isotope database: the
Los Pedroches-Alcudia area (Spain); implications for archaeometallurgical connections across southwestern and southeastern Iberia", Archaeometry, 46 (4), pp. 625-634.

Stos-Gale, Z. A. (1990): "Lead isotope studies of metals and the Metals trade in the Bronze Age Mediterranean". En Henderson, J. (ed.): Scientific Analysis in Archaeology. Monograph, 19. Oxford: University Committee, pp. 274-301.

Stos-Gale, Z. A.; Gale, N. H.; Houghton, J. y Speakman, R. (1995): "Lead isotope data from the isotrace laboratory, Oxford: Archaeometry data base 1, ores from the western Mediterranean", Archaeometry, 37 (2), pp. 407-415.

Stos-Gale, Z. A.; Hunt, M. y Gale, N. H. (1999): "Análisis elemental de isótopos de plomo de objetos metálicos de Gatas". En Castro, P.; Chapman, R.; Gili, S.; Lull, V.; Micó, R.; Rihuete, C.; Risch, R. y Sanahuja, M. E. (eds.): Proyecto Gatas 2. La Dinámica Arqueológica de la ocupación prehistórica. Sevilla: Junta de Andalucía, pp. 347-358.

Tornos, R. y Chiaradia, M. (2004): "Plumbotectonic Evolution of the Ossa Morena Zone: Iberian Peninsula: Tracing the Influence of Mantle-Crust Interaction in Ore-Forming Processes", Economic Geology, 99, pp. 965-985.

Tovar, A.; Marqués, I.; Jiménez Brobeil, S. y AguaDo, T. (2014): "El hipogeo número 14 de la necrópolis de Alcaide (Antequera, Málaga): Un enterramiento colectivo de la Edad del Bronce", Menga, 5, pp. 123-149. 